\title{
CHEMICAL ACTIVATION OF MOLECULES BY METALS: EXPERIMENTAL STUDIES OF ELECTRON DISTRIBUTIONS AND BONDING
}

\section{FINAL REPORT SUMMARY}

The following specific research accomplishments have taken place during the most recent period of support from DOE: (a) We have characterized the electronic, thermodynamic, and mechanistic principles of protonation of organometallic molecules in cases where protonation leads to formation of a carbon-hydrogen bond before formation of a metal-hydride, which is normally the thermodynamic product. (b) We have examined the ionizations of the polyhydride molecule $\mathrm{ReH}_{7}\left(\mathrm{PMe}_{3}\right)_{2}$, a molecule that is remarkably stable in aqueous solution and resistant to loss of $\mathrm{H}_{2}$. (c) We have investigated the electron distribution of the early transition metal carbonyl molecules $\left(?^{5}-\mathrm{C}_{5} \mathrm{H}_{5}\right) \mathrm{M}(\mathrm{CO})_{4} \quad(\mathrm{M}=\mathrm{V}, \mathrm{Nb}, \mathrm{Ta})$. In contrast to the results for later transition metals, we find that the frontier electron density is much more delocalized to the carbonyls, to the extent that substitutions on the cyclopentadienyl rings and even substitution of one metal for the other has little effect on the valence electronic properties. (d) We have studied the influence of metal electron richness upon the interactions of alkynyls (also called acetylides) with metals. Photoelectron spectroscopy is the only technique that can provide an experimental separation of the alkynyl s, p, and $\mathrm{p}^{*}$ interactions with the metal. In addition to the common occurrence of metal-alkynyls in catalytic systems, these complexes are also of interest for nonlinear optical properties. (e) We have investigated the ability of conjugated organic molecules to facilitate electronic communication between two metals. An example is two iron atoms linked by two fulvalene ligands, which may be viewed as two ferrocenes with linked cyclopentadienyl rings. Changes in the linkage cause changes in the electronic interactions according to distance and orbital symmetry interactions. (f) We have published a review of the spectroscopy and theory of metal-carbonyls and metallocenes and discussed the challenges that remain in understanding the electronic structure and bonding in these classes of molecules. (g) We have compared the bonding of benzene and $\mathrm{C}_{60}$ to the metal cluster $\mathrm{Ru}_{3}(\mathrm{CO})_{9}$. The principal metal-arene bonding modes are much the same in both systems, but the more band-like electronic structure of the fullerene (i.e., the greater number density of donor and acceptor orbitals in a given energy region) as compared to $\mathrm{C}_{6} \mathrm{H}_{6}$ permits a greater degree of electron flow and stronger bonding between the $\mathrm{Ru}_{3}(\mathrm{CO})_{9}$ and $\mathrm{C}_{60}$ clusters. (h) Additional progress is reported on collaborative studies of metal-alkyls, metalnitrosyls, metal-thiolates, metal-disilenes, and metal-amides. All of these studies have contributed significantly to expanding our understanding of the electronic structure and bonding of organic molecules to metals and the ways these metal interactions alter the properties of the organic molecules. In addition, we have continued to develop the experimental and theoretical methods for these studies. Experiments have begun with a new UHV surface electron spectrometer, and funds have been obtained to construct a new gas-phase photoelectron spectrometer that will greatly extend the capabilities of this research. Perhaps most significantly, the experimentation has expanded into new and exciting studies of the ionization spectroscopy of non-volatile organometallic molecules, solvated molecules, coordinatively unsaturated metal centers, and metalloenzymes that are important to catalysis and vital to energy research. 


\title{
CHEMICAL ACTIVATION OF MOLECULES BY METALS: EXPERIMENTAL STUDIES OF ELECTRON DISTRIBUTIONS AND BONDING
}

\author{
CONTENTS
}

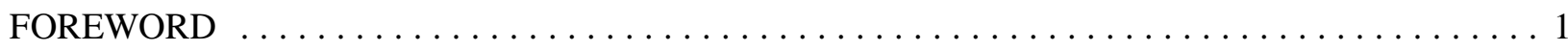

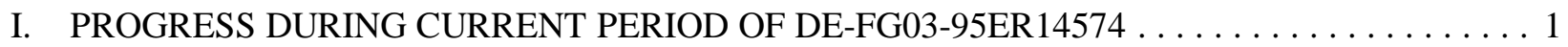

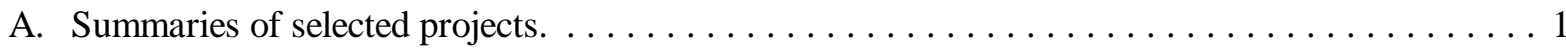

1. Electronic Factors for Protonation of an Organometallic Molecule. A Photoelectron Spectroscopy and Electron Paramagnetic Resonance Study of $\left.\left(?^{6}-\mathrm{C}_{6} \mathrm{H}_{6}\right) \mathrm{Mo}(\mathrm{TRIPOD})\right]^{0 /+} \ldots 1$

2. A Comparative Study of the Isomers of $\mathrm{ReOCl}_{3}\left(\mathrm{PMe}_{3}\right)_{2}$ and $\mathrm{ReO}(\mathrm{OEt}) \mathrm{Cl}_{2}\left(\mathrm{PR}_{3}\right)_{2}$. The isolation and characterization of $\mathrm{ReH}_{7}\left(\mathrm{PR}_{3}\right)_{2}$ and $\mathrm{ReO}(\mathrm{OEt}) \mathrm{Cl}_{2}\left(\mathrm{PR}_{3}\right)_{2}(\mathrm{R}=\mathrm{Me}$ or $\mathrm{Et})$ and the

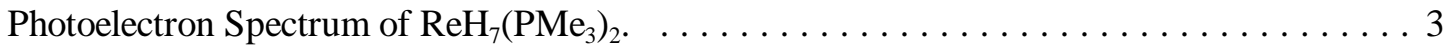

3. Electronic Structure of Early Transition-Metal Carbonyls: The Gas-Phase Photoelectron

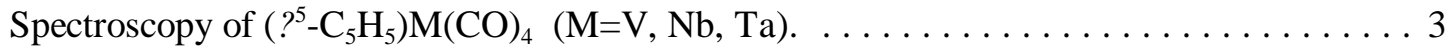

4. Experimental Measures of Metal-Alkynyl Electronic Structure in $\left(?^{5}-\mathrm{C}_{5} \mathrm{H}_{5}\right) \mathrm{Ru}(\mathrm{CO})_{2} \mathrm{C} / \mathrm{CMe}$ and $\left.\left(?^{5}-\mathrm{C}_{5} \mathrm{H}_{5}\right) \mathrm{Ru}(\mathrm{CO})_{2}\right]_{2}(\mu-\mathrm{C} / \mathrm{C})$ by Photoelectron Spectroscopy. $\ldots \ldots \ldots \ldots \ldots \ldots 4$

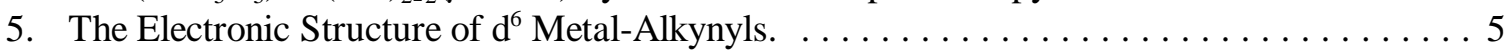

6. Ligand-Mediated Metal-Metal Interactions and Localized versus Delocalized Mixed-Valence Cation States of Biferrocene and Bis( $\mu$-fulvalenediyl)diiron in the Gas Phase by Valence Photoelectron Spectroscopy; $\left[\right.$ Fulvalene $\left.=\left(?^{5}-\mathrm{C}_{5} \mathrm{H}_{4}: ?^{5}-\mathrm{C}_{5} \mathrm{H}_{4}\right)\right] \ldots \ldots \ldots \ldots \ldots \ldots$

7. Characterization of the Electronic Structure of Transition Metal Carbonyls and Metallocenes

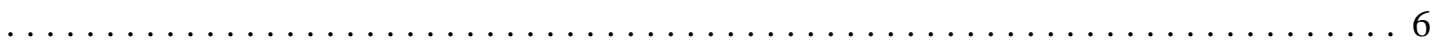

8. Comparison of the Bonding of Benzene and $\mathrm{C}_{60}$ to a Metal Cluster: $\mathrm{Ru}_{3}(\mathrm{CO})_{9}\left(\mu^{3}-?^{2}, ?^{2}, ?^{2}-\right.$

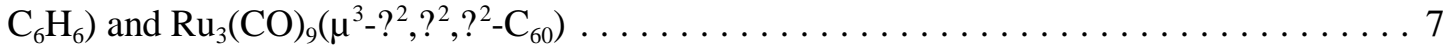

9. Ligand Effects on Metal-Metal Interactions: The Relationship Between Rh-Rh Bonding and

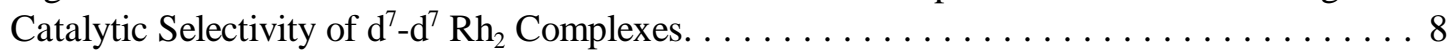

10. Preparation, Characterization and Electronic Structure of $\mathrm{W}_{2}\left(\mathrm{NMe}_{2}\right)_{2}\left(\mathrm{OR}_{\mathrm{f}}\right)_{4}$, Where $\mathrm{R}_{\mathrm{f}}=$ $\mathrm{CMe}_{2} \mathrm{CF}_{3}, \mathrm{CMe}\left(\mathrm{CF}_{3}\right)_{2}$, and $\mathrm{C}\left(\mathrm{CF}_{3}\right)_{3}$ as Deduced by Photoelectron Spectroscopic Studies and

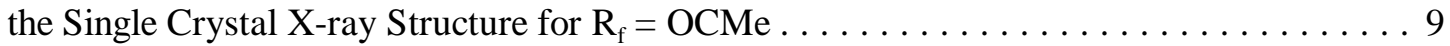

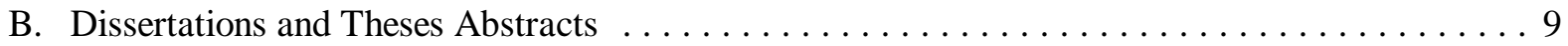

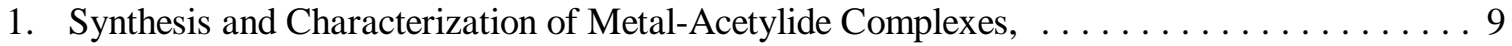

2. Photoelectron Spectroscopy and Computational Studies of Electron Delocalization in

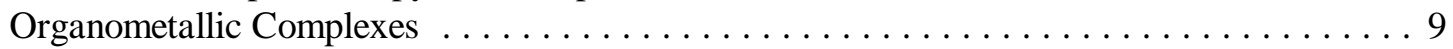

3. Metal, Ligand, and Symmetry Influences on Metal-Metal Bonds: Photoelectron Spectroscopy

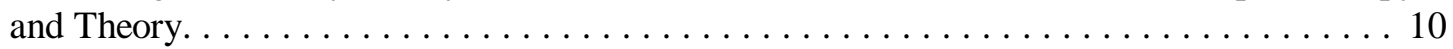

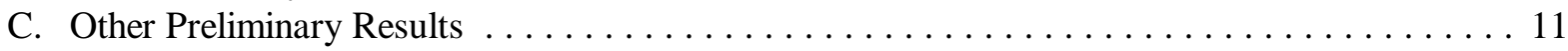

1. Electronic Structure and Relative $\mathrm{Fe}-\mathrm{H}$ and $\mathrm{Fe}-\mathrm{CH}_{3}$ Bond Dissociation Energies of (? ${ }^{5}-$ $\left.\mathrm{C}_{5} \mathrm{R}_{5}\right) \mathrm{Fe}(\mathrm{CO})_{2} \mathrm{R}$ Compounds $\left(\mathrm{R}=\mathrm{H}\right.$ or $\left.\mathrm{CH}_{3}\right)$ from Photoelectron Spectroscopy $\ldots \ldots \ldots 11$

2. Electronic Interactions in $\mathrm{CpRe}(\mathrm{NO})(\mathrm{L}) \mathrm{R}$ Complexes $\left[\mathrm{Cp}=?^{5}-\mathrm{C}_{5} \mathrm{H}_{5}, ?^{5}-\mathrm{C}_{5}\left(\mathrm{CH}_{3}\right)_{5} ; \mathrm{L}=\mathrm{CO}\right.$, $\left.\left.\mathrm{P}\left(\mathrm{C}_{6} \mathrm{H}_{5}\right)_{3} ; \mathrm{R}=\mathrm{H}, \mathrm{CH}_{3}\right)\right]$ : Comparison of Re-H Bond Ionizations with $\mathrm{Re}-\mathrm{CH}_{3}$ Bond

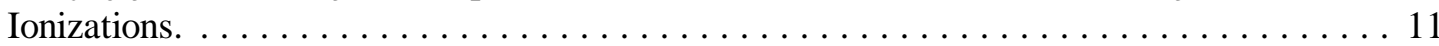

3. Oxidative Addition to Rhodium and Iridium Complexes. . . . . . . . . . . . . . . . 13

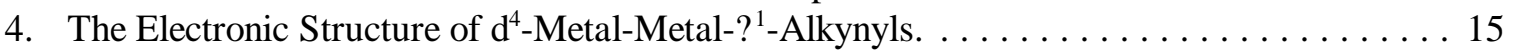

5. Gas-Phase Photoelectron Spectroscopy of CpNiNO and Cp*NiNO: A "Resolution" to the Controversy. 
6. Photoelectron Spectroscopy of Chiral Thiolate Complexes of the Type $\mathrm{CpM}(\mathrm{NO})(\mathrm{L}) \mathrm{SMe}(\mathrm{M}=$

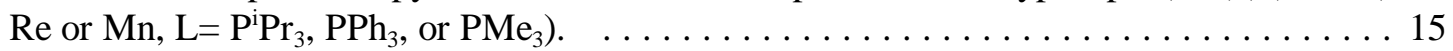

7. Quantitative Evaluation of the Metal-Halide $\mathrm{p}$ Interactions for Rhenium Pentacarbonyl Halidæ5

8. Geometry and Substituent Effects on the Electronic Structure of Disilenes . . . . . . . 16

9. Comparison of the Electronic Structure of Disilene, Silene, and Olefin Transition Metal

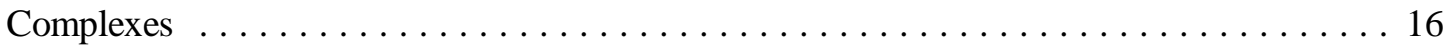

10. Comparison of the Bonding in Chelated Triphos and Tris(tertiary amine) Rhodium Complexes6 11. Photoelectron Spectroscopy of Methyl-Substituted Ferrocenes. . . . . . . . . . . . . 17

D. INSTRUMENTATION AND METHODS DEVELOPMENT $\ldots \ldots \ldots \ldots \ldots \ldots \ldots \ldots 17$

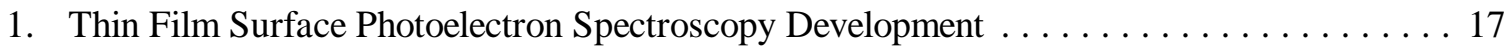

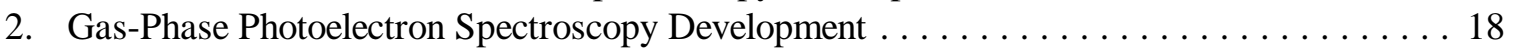

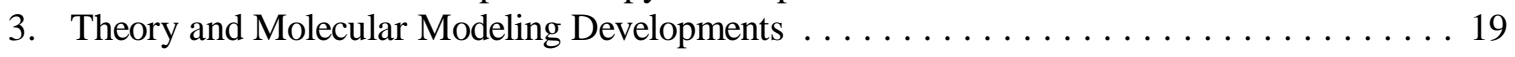

II. LIST OF PUBLICATIONS AND PRESENTATIONS, September $1995-2000 \ldots \ldots \ldots \ldots$

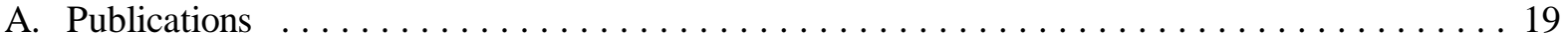

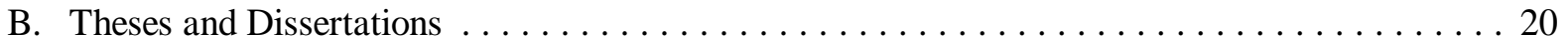

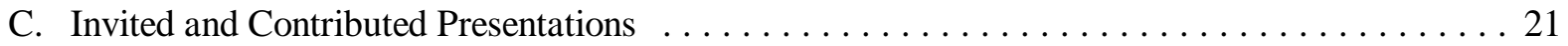

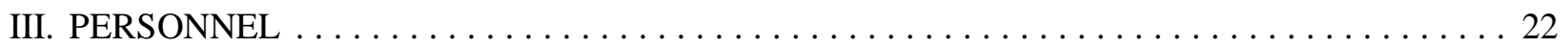

A. Postdoctoral Associates, Graduate Students, Undergraduates, and Staff, 1995-2000 . . . . . 22

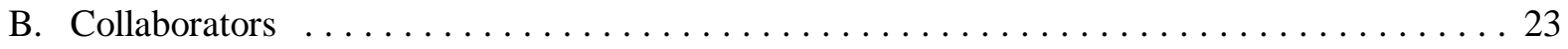




\section{CHEMICAL ACTIVATION OF MOLECULES BY METALS: EXPERIMENTAL STUDIES OF ELECTRON DISTRIBUTIONS AND BONDING}

\section{FOREWORD}

This report collects some of the accomplishments of this research program. We are pleased to report that the research in this project has continued to be successful and rewarding. several notable accomplishments have occurred during this period of the project that have not only provided new levels of understanding of the electronic factors of bond activation and reactivity in catalysis, but have also opened up excellent opportunities for a broader scope of investigations in the future. This progress report gives brief summaries of selected results from publications, dissertations, and meeting presentations (section II). In the last twelve months alone, twelve papers were completed, with four of these in the Journal of the American Chemical Society. During this period we have also acquired a new state-of-the-art small spot UHV surface analysis system (section IID), obtained new funding for construction of a next-generation gas-phase photoelectron spectrometer, accomplished several developments in theoretical modeling and computational chemistry, and initiated many new collaborations.

More important than the quantity of the work, there has been an increasing impact of the work on current problems and areas of research in basic energy sciences. Our publications have been cited more than 1400 times in recent years (Science Citation Index), and numerous collaborations have developed as a result of this research (section IVB). These collaborations have developed from the interest we share with other researchers in the chemical systems that are important to energy research and from our unique capabilities for obtaining experimental measures of electronic structure that are useful to other researchers. Nearly 50 researchers with support from the Department of Energy have been either direct collaborators with the PI or have shared interest in these chemical systems. As a consequence, we have been able to contribute to a wide diversity of research studies, as is apparent from the topics in section II.

In addition to the continuing application of our methods to chemical systems of current interest, we also have been developing the instrumentation of gas-phase photoelectron spectroscopy for the study of molecules with low volatility or stability, and we have further developed our methods for surface electron spectroscopy. Our directions in this latter area are particularly important, because they offer an approach to the valence

photoelectron spectroscopy of non-volatile molecules, and they bridge the characterization of molecules in the gas phase to characterization of molecules in 'solvated' environments.

\section{PROGRESS DURING CURRENT PERIOD OF DE-FG03-95ER14574}

\section{A. Summaries of selected projects.}

1. Electronic Factors for Protonation of an Organometallic Molecule. A Photoelectron Spectroscopy and Electron Paramagnetic Resonance Study of $\left({ }^{{ }^{6}}{ }^{6} \mathbf{C}_{6} \mathbf{H}_{6}\right) \mathbf{M o}($ TRIPOD$\left.)\right]^{0 /+}$. V.S. Asirvatham, N.E. Gruhn, D.L. Lichtenberger and M.T. Ashby, Organometallics 2000, 19, 2215-2227.

Protonation reactions for the formation of carbon-hydrogen bonds are important in hydrogenation reactions. We have previously shown that the arene complex $\left(?^{6}-\mathrm{C}_{6} \mathrm{H}_{6}\right) \mathrm{Mo}$ (TRIPOD), where TRIPOD $=1,1,1$ - 
tris(diphenylphosphinomethyl)ethane, is protonated by exo addition of $\mathrm{H}^{+}$to the arene ring to give a transient cyclohexadienyl complex $\left[\left(?^{5}-\mathrm{C}_{6} \mathrm{H}_{7}\right) \mathrm{Mo}(\mathrm{TRIPOD})\right]^{+}$that eventually yields the thermodynamic molybdenumhydride $\left[\left(?^{6}-\mathrm{C}_{6} \mathrm{H}_{6}\right) \mathrm{Mo}(\mathrm{TRIPOD})(\mathrm{H})\right]^{+}$. The example with deuteration is shown below. This publication reports

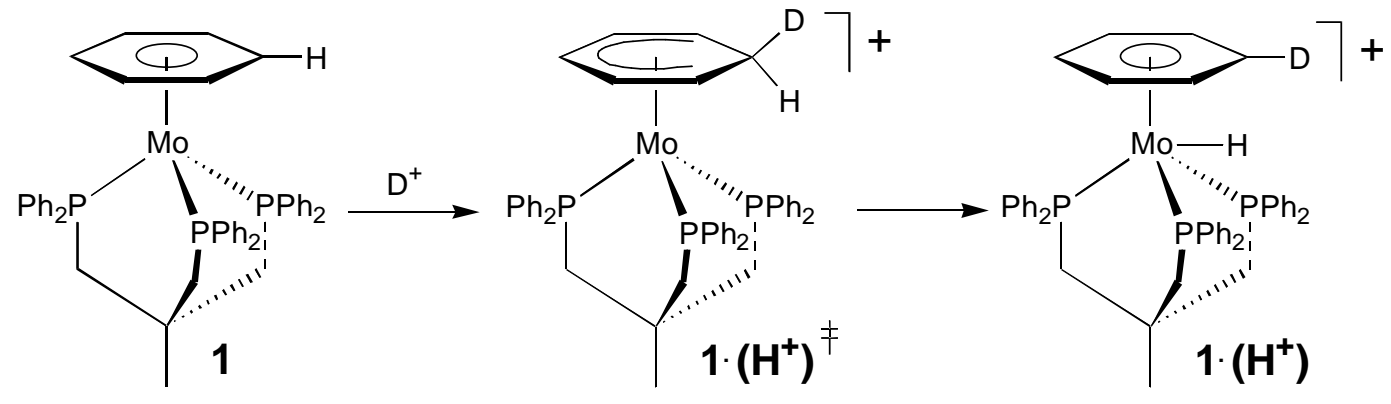

a combined experimental and theoretical investigation that reveals the fundamental basis for this mechanism. Photoelectron spectroscopy was used to probe the electronic structure of $\left(?^{6}-\mathrm{C}_{6} \mathrm{H}_{6}\right) \mathrm{Mo}$ (TRIPOD) and the production of the $\left[\left(?^{6}-\mathrm{C}_{6} \mathrm{H}_{6}\right) \mathrm{Mo}(\mathrm{TRIPOD})\right]^{+}$cation in the gas-phase. The initial ionizations of $\left[\left(?^{6}-\mathrm{C}_{6} \mathrm{H}_{6}\right) \mathrm{Mo}\right.$ (TRIPOD)] are from orbitals of predominantly metal $\mathrm{d}$ character $\left({ }^{2} \mathrm{~A}_{1}\right.$ and ${ }^{2} \mathrm{E}$ cation states using $\mathrm{C}_{3 \mathrm{v}}$ symmetry) that are shifted over $2 \mathrm{eV}$ to lower energy with respect to the comparable ionizations of $\left(?^{6}-\mathrm{C}_{6} \mathrm{H}_{6}\right) \mathrm{Mo}(\mathrm{CO})_{3}$. These metal-based ionizations are close in energy and there is evidence for Jahn-Teller distortion of the ${ }^{2} \mathrm{E}$ positive ion state. Electronic structure calculations show that this distortion is characterized by the opening of one L-Mo-L angle, which effectively creates an open coordination site on the metal for the hydride to occupy in the final thermodynamic product. The oxidized species $\left[\left(?^{6}-\mathrm{C}_{6} \mathrm{H}_{6}\right) \mathrm{Mo}(\mathrm{TRIPOD})\right]^{+}$also is prepared in solution electrochemically and through the use of chemical oxidants. The EPR spectrum of this cation shows a large arene-proton hyperfine coupling that indicates substantial arene character in the highest occupied orbital.

The relationship between the protonation of a molecule and the ionization of that molecule is explicit in thermodynamics. The protonation energy is equivalent to the ionization energy (IE) of the molecule minus the ionization energy of the hydrogen atom and the homolytic bond energy (BE) to the hydrogen atom, as represented by the stepwise process below (where negative signs indicate stabilization):

$$
M+H^{+} \stackrel{\Delta H_{I E}(M)}{-\Delta H_{I E}(H)}[M \cdot]^{+}+H \cdot \stackrel{-\Delta H_{B E}\left([M-H]^{+}\right)}{\longrightarrow}[M-H]^{+}
$$

The thermodynamically favored process will involve the lowest ionization energy state of the molecule and formation of the strongest homolytic bond to hydrogen in the positive ion. These photoelectron results show that, in terms of their energy, the e symmetry and $a_{1}$ symmetry metal-based orbitals are similarly favored for oxidative protonation directly at the metal. The e symmetry orbital has a portion of its density on the arene ring, making access to this orbital by proton approach to the exo position of the arene ring possible. For $\left(?^{6}-\mathrm{C}_{6} \mathrm{H}_{6}\right) \mathrm{Mo}$ (TRIPOD), exo attack at the arene is favored because the TRIPOD ligand shields the e symmetry orbital from direct attack at the metal by the solvated proton. Thus, exo attack is not initiated by proton interaction with an arene-based orbital, but is initiated by proton interaction with the arene portion of the same e symmetry orbital that directs attack at the metal. Calculations predict low barriers for both direct attack at the metal and exo attack at the arene, with attack at the arene favored for longer metal-proton distances. 
2. A Comparative Study of the Isomers of $\operatorname{ReOCl}_{3}\left(\mathrm{PMe}_{3}\right)_{2}$ and $\mathrm{ReO}(\mathrm{OEt}) \mathrm{Cl}_{2}\left(\mathrm{PR}_{3}\right)_{2}$. The isolation and characterization of $\operatorname{ReH}_{7}\left(\mathrm{PR}_{3}\right)_{2}$ and $\operatorname{ReO}(\mathrm{OEt}) \mathrm{Cl}_{2}\left(\mathrm{PR}_{3}\right)_{2}(\mathrm{R}=\mathrm{Me}$ or $\mathrm{Et})$ and the Photoelectron Spectrum of $\mathbf{R e H}_{7}\left(\mathbf{P M e}_{3}\right)_{2}$. K. J. Smith, A. L. Ondracek, N. E. Gruhn, D. L. Lichtenberger, P. E. Fanwick, and R. A. Walton, Inorg. Chim. Acta 2000, 300-302, 23-31.

Metal-hydrides are important in homogeneous and heterogeneous catalysis. The reactions of mer-trans$\mathrm{ReOCl}_{3}\left(\mathrm{PPh}_{3}\right)_{2}$ with $\mathrm{PMe}_{3}$ and $\mathrm{PEt}_{3}$ provide a route to the isomers fac-cis- $\mathrm{ReOCl}_{3}\left(\mathrm{PR}_{3}\right)_{2}$ and mer-trans$\mathrm{ReOCl}_{3}\left(\mathrm{PR}_{3}\right)_{2}\left(\mathrm{R}=\mathrm{Me}\right.$ or Et) which can be converted to $\mathrm{ReH}_{7}\left(\mathrm{PR}_{3}\right)_{2}(\mathrm{R}=\mathrm{Me}$ or Et $)$ in ca. $60 \%$ yield by reaction with $\mathrm{LiAIH}_{4}$ in THF and subsequent hydrolysis of the reaction mixtures. The properties of these heptahydrides have been examined, including studies of the remarkable stability of aqueous solutions of $\mathrm{ReH}_{7}\left(\mathrm{PMe}_{3}\right)_{2}$ and the little tendency to eliminate $\mathrm{H}_{2}$. The gas-phase $\mathrm{He}(\mathrm{I})$ photoelectron spectrum of this complex shows a near continuum of ionizations from 8 to $11 \mathrm{eV}$, where the seven Re-H bond pair ionizations and the two Re-P bond ionizations are expected to occur. No feature in this region has the appearance of a rhenium d-orbital ionization, consistent with the interpretation of this molecule as a $\operatorname{Re}(\mathrm{VII}) \mathrm{d}^{0}$ heptahydride with only classical hydride ligands and without a tendency to form dihydrogen bonding with the metal. The 'continuum' of ionizations between 8-11 eV follows from the mixing of the nine metal-ligand sigma bonds.

3. Electronic Structure of Early Transition-Metal Carbonyls: The Gas-Phase Photoelectron Spectroscopy of $\left(?^{5}-\mathbf{C}_{5} \mathbf{H}_{5}\right) \mathbf{M}(\mathbf{C O})_{4}(\mathbf{M = V}, \mathbf{N b}, \mathbf{T a})$. D. L. Lichtenberger, H.-J. Fan, N. E. Gruhn, T. E. Bitterwolf, S. Gallagher, Organometallics 2000, 19, 2012-2021.

The recent publication of a new synthesis route to $\mathrm{CpM}(\mathrm{CO})_{4}$ molecules $\left(\mathrm{Cp}=?^{5}\right.$ cyclopentadienyl, $\mathrm{M}=\mathrm{V}, \mathrm{Nb}, \mathrm{Ta}$ ) has made detailed spectroscopic studies of these molecules and their derivatives feasible. Infrared spectroscopic studies indicate that the carbonyl stretching frequencies of these molecules do not change greatly upon addition of substituents on the $\mathrm{Cp}$ ligand or with change of the metal center. For example, the carbonyl stretching frequencies of $\mathrm{CpNb}(\mathrm{CO})_{4}, \mathrm{CpTa}(\mathrm{CO})_{4},\left(?^{5}-\right.$ $\left.\mathrm{C}_{5} \mathrm{H}_{4} \mathrm{Si}\left(\mathrm{CH}_{3}\right)_{3}\right) \mathrm{Nb}(\mathrm{CO})_{4},\left(?^{5}-\mathrm{C}_{5} \mathrm{H}_{4} \mathrm{Si}\left(\mathrm{CH}_{3}\right)_{3}\right) \mathrm{Ta}(\mathrm{CO})_{4}$ are almost the same within the

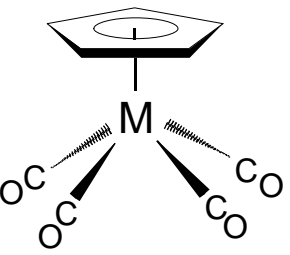
$\mathrm{M}=\mathrm{V}, \mathrm{Nb}, \mathrm{Ta}$ experimental certainty. The insensitivity of the carbonyl stretching frequencies to changes in the metal or to substituents on the ring are in contrast to previous systems we have studied. This provoked our interest in studying the factors that control the electron flow upon the substitution on the ring and replacement of the metal center for these early transition metal systems.

Gas-phase photoelectron spectroscopy was used to investigate the bonding between early transition metals and carbonyl and cyclopentadienyl ligands for the molecules $\left(?^{5}-\mathrm{C}_{5} \mathrm{H}_{4} \mathrm{R}\right) \mathrm{M}(\mathrm{CO})_{4}\left(\mathrm{R}=\mathrm{H}, \mathrm{M}=\mathrm{V}, \mathrm{Nb}, \mathrm{Ta} ; \mathrm{R}=\mathrm{SiMe}_{3}, \mathrm{M}=\mathrm{Nb}, \mathrm{Ta}\right.$; $\mathrm{R}=\mathrm{COCH}_{3}, \mathrm{M}=\mathrm{Nb}$ ). The lowest ionization energy region (7-8 eV) contains two overlapping ionizations that arise from the two orbitals that are occupied according to the formal $\mathrm{d}^{4}$ metal configuration. However, the character of these ionizations is dominated by the carbonyls rather than by the metals, as evidenced by the extensive $\mathrm{C}-\mathrm{O}$ stretching vibrational progressions observed with these ionizations, by the trends in the ionization cross sections between the molecules and with different ionization sources, and by the relative lack of shifts of these ionizations with metal substitution from vanadium to niobium to tantalum or with trimethylsilyl and acetyl substitutions on the cyclopentadienyl. The second group of ionizations for these molecules $(9-11 \mathrm{eV})$ corresponds to orbitals with predominantly cyclopentadienyl $\mathrm{p}$ character that donate to empty metal $\mathrm{d}$ orbitals. A larger shift of these ionizations is observed upon cyclopentadienyl substitution. The molecular structures are sensitive to the electron configurations. Both density

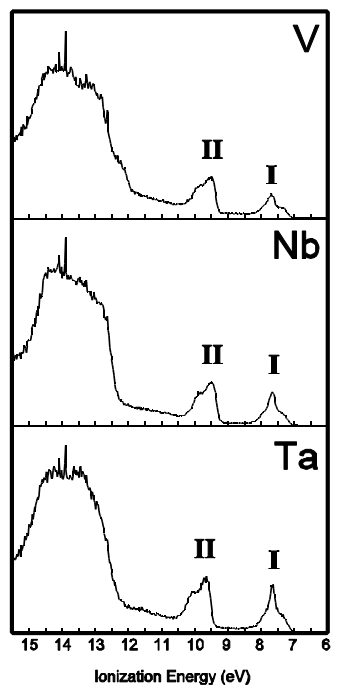


functional theory and ab initio calculations reproduce well the geometry of the neutral molecules and also predict the geometry changes upon ionization. The first ionization, which relates to an orbital with the $\mathrm{a}_{1}$ symmetry of the metal $\mathrm{d}_{\mathrm{z}^{2}}$ orbital, is broad due to a substantial geometry change upon removal of an electron from this orbital. The shoulder on the cyclopentadienyl-based ionizations relates to a dynamic Jahn-Teller geometrical distortion. The unusually large metal-to-carbonyl backbonding observed in these molecules is facilitated by the interligand overlap between the four carbonyls, which substantially stabilizes the appropriate symmetry-adapted carbonyl $\mathrm{p}^{*}$ acceptor orbitals. The extensive carbonyl character in the valence electronic structure diminishes any trends in properties with substitutions of the metals down the group or with substitutions on the cyclopentadienyl ring.

4. Experimental Measures of Metal-Alkynyl Electronic Structure in $\left(?^{5}-\mathrm{C}_{5} \mathrm{H}_{5}\right) \mathrm{Ru}(\mathrm{CO})_{2} \mathrm{C} / \mathrm{CMe}$ and $\left.\left(?^{5}-\mathrm{C}_{5} \mathrm{H}_{5}\right) \mathrm{Ru}(\mathrm{CO})_{2}\right]_{2}(\mu-\mathrm{C} / \mathrm{C})$ by Photoelectron Spectroscopy. Lichtenberger, D. L.; Renshaw, S. K.; Uplinger, A. B.; Selegue, J. P.; Lomprey, J.

Alkynyls are important species in many metal surface catalytic reactions. One very basic question is whether the interaction of the alkynyl with the metal is dominated by electron donation from the filled $\mathrm{C}=\mathrm{C} \mathrm{p}$ bond to the metal or whether the interaction is dominated by electron acceptance into the $\mathrm{C}=\mathrm{C} \mathrm{p}^{*}$ antibond from filled metal orbitals. Other methods have only been able to sense the net charge distribution at the metal or the effects of the $\mathrm{C}=\mathrm{C} \mathrm{p}^{*}$ orbital. Our photoelectron spectroscopy measurements have been able to separate by symmetry the metal-alkynyl $\mathrm{p}$ interactions from the $\mathrm{s}$ interactions, and have shown that the alkynyl $\mathrm{p}$ interaction is energetically more significant than the $\mathrm{p}^{*}$ interaction, although we were not able to separate the $\mathrm{p}$ and $\mathrm{p}^{*}$ interactions. This separation has now been accomplished with the novel system below.

The gas-phase He I and He II photoelectron spectra of the propynylruthenium molecule $\left(?{ }^{5}-\mathrm{C}_{5} \mathrm{H}_{5}\right) \mathrm{Ru}(\mathrm{CO})_{2} \mathrm{C} / \mathrm{CMe}$ and the ethynediyldiruthenium molecule $\left[\left(?^{5}-\right.\right.$ $\left.\left.\mathrm{C}_{5} \mathrm{H}_{5}\right) \mathrm{Ru}(\mathrm{CO})_{2}\right]_{2}(\mu-\mathrm{C} / \mathrm{C})$ have been collected and compared with the spectrum of $\left(?^{5}-\mathrm{C}_{5} \mathrm{H}_{5}\right) \mathrm{Ru}(\mathrm{CO})_{2} \mathrm{Cl}$ to experimentally determine the predominant electronic structure interactions of the alkynyl ligand

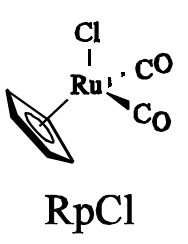
with the metal. Ionizations originating from the metal $\left(\mathrm{d}^{6}\right)$ orbitals, the alkynyl $\mathrm{p}$ and chloride $\mathrm{p}$ symmetry orbitals, the $\mathrm{Cp} e_{1}^{\mathrm{O}}\left(\mathrm{Cp}=?^{5}-\mathrm{C}_{5} \mathrm{H}_{5}\right)$ orbitals, and the ruthenium-carbon and ruthenium-chloride $\mathrm{s}$ bonding orbitals are clearly seen for $\mathrm{CpRu}(\mathrm{CO})_{2} \mathrm{C} / \mathrm{CMe}$ and $\mathrm{CpRu}(\mathrm{CO})_{2} \mathrm{Cl}$. The filled/filled interaction between the metal-dp and alkynyl-p orbitals dominates the metal-alkynyl p electronic structure, mirroring previously characterized $\mathrm{CpFe}(\mathrm{CO})_{2}$-alkynyls. All valence ionizations of the ruthenium molecules are stabilized with respect to the ionizations of the similar iron compounds, as observed for other first and second row transition metal molecules and contrary to the common expectation of lower ionization energies with atomic substitution down a column of the periodic table. Ab initio atomic and molecular orbital calculations suggest that this stabilization traces to the greater inherent electronic relaxation energy associated with removal of iron $3 \mathrm{~d}$ electrons compared to removal of ruthenium $4 \mathrm{~d}$ electrons. This point is being investigated further in a separate study. 
DE-FG03-95ER14574

\begin{abstract}
The diruthenium

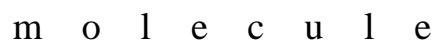
$\left[\left(?^{5}-\mathrm{C}_{5} \mathrm{H}_{5}\right) \mathrm{Ru}(\mathrm{CO})_{2}\right]_{2}(\mu-$ $\mathrm{C} / \mathrm{C})$ produced a significantly destabilized first ionization band, indicating that electronic communication is occurring between the metals by means of symmetry mixing with the alkynyl bridge. The first two ionization bands of the diruthenium molecule correspond principally to the symmetric
\end{abstract} (with respect to an effective

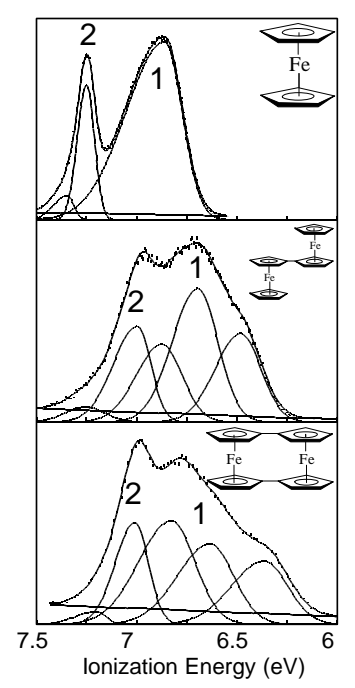

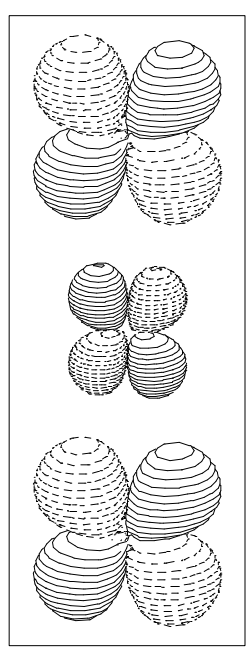

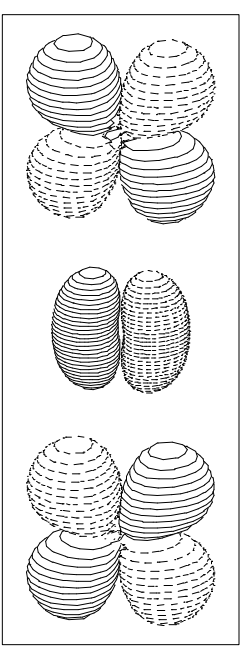

mirror plane perpendicular to the $\mathrm{Ru}-\mathrm{C} / \mathrm{C}-\mathrm{Ru}$ axis) combination of metal-metal-dp orbitals, which are destabilized by filled-filled interaction with the alkynyl $\mathrm{p}$ bonds as shown by the orbital figure at the far right. At greater energy are ionizations arising from the antisymmetric combination of the metal-metal-dp orbitals, which are stabilized by interaction with the alkynyl $\mathrm{p}^{*}$ orbitals as shown by the middle orbital diagram in the figure. The ionization energy shifts of the antisymmetric combinations indicate the extent the metal-metal-dp orbitals are stabilized by backbonding into the alkynyl $\mathrm{p}^{*}$ orbitals. The stabilization of metal-based ionizations caused by the backbonding interaction to the alkynyl $\mathrm{p}^{*}$ orbitals is found to be approximately one-third of the destabilization caused by the filled-filled interaction with the alkynyl $\mathrm{p}$ bonds and about one-fourth to one-third the stabilization provided by a carbonyl ligand. This is the first quantitative comparison of these electronic structure interactions.

5. The Electronic Structure of $\mathbf{d}^{6}$ Metal-Alkynyls. D. L. Lichtenberger, S. K. Renshaw, A. B. Uplinger, R. M. Bullock (Brookhaven National Laboratory), and M. G. Humphrey (Australian National University). "The Electronic Structure of Metal Acetylides." Andrew B. Uplinger, Ph.D. Dissertation Diss. Abstr. Int., $B$ 1998, 59 (5), 2197; The University of Arizona: Tucson, Arizona; 225 pp.(DOE)

In order to measure the influences of substituents on the alkynyls on the electronic interactions with the metal, gas-phase ultraviolet photoelectron spectroscopy has been used to investigate the electronic structure and bonding interactions of $\mathrm{d}^{6}$ piano-stool metal-alkynyls of the general formulas $\mathrm{CpML}_{2} \mathrm{C} / \mathrm{C}-\mathrm{R}\left[\mathrm{M}=\mathrm{Ru} ; \mathrm{L}=\mathrm{PMe}_{3} ; \mathrm{R}=\mathrm{H}\right.$, $\left.\mathrm{Me},{ }^{\mathrm{t}} \mathrm{Bu}, \mathrm{C}_{6} \mathrm{H}_{5}\right]$ and $\mathrm{CpML}_{2} \mathrm{C} / \mathrm{C}-\mathrm{p}-\mathrm{C}_{6} \mathrm{H}_{4}-\mathrm{NO}_{2}[\mathrm{M}=\mathrm{Fe}, \mathrm{Ru} ; \mathrm{L}=\mathrm{CO}$; and $\mathrm{M}=\mathrm{Ru}$; $\mathrm{L}=\mathrm{PMe}_{3}$ ]. Previous studies of analogous $\mathrm{CpFe}(\mathrm{CO})_{2} \mathrm{C} / \mathrm{C}-\mathrm{R}$ complexes found that

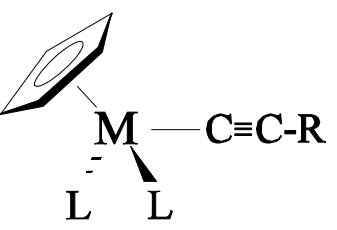
the filled-filled interaction between the metal $\mathrm{d}$ electrons and the acetylide $\mathrm{p}$ bond electrons dominates the shift of the first valence ionizations, and that backbonding of the metal d electrons into the alkynyl $\mathrm{p}^{*}$ orbitals is very small. It is found here that the change to the second row transition metal and the substitution of phosphines for the carbonyls makes the metal more electron rich, but does not change the basic description of the metal interaction with the acetylide.

6. Ligand-Mediated Metal-Metal Interactions and Localizedversus Delocalized Mixed-Valence Cation States of Biferrocene and Bis( $\mu$-fulvalenediyl)diiron in the Gas Phase by Valence Photoelectron Spectroscopy; [Fulvalene $\left.=\left({ }^{5}-\mathbf{C}_{5} \mathbf{H}_{4}: ?^{5}-\mathbf{C}_{5} \mathbf{H}_{4}\right)\right]$. Huajun Fan. Ph.D. Dissertation: The University of Arizona, 1999.(DOE)

The bis(fulvalene)diiron complex has interesting possibilities for both through-

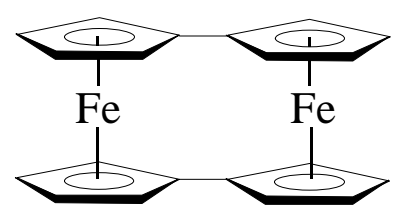


space and through-ligand metal-metal interactions. Gas-phase photoelectron spectroscopy is used to investigate metal-metal interactions and the mixed-valence positive ion states of biferrocene and $b i s(\mu$-fulvalenediyl)diiron. The spectra of phenylferrocene and 1,1'-diphenylferrocene are used to show that, in comparison to ferrocene, the extension of the ligand $\mathrm{p}$ system and the reduced ligand symmetry do not have an appreciable effect on the band profile of the metal-based ionizations. In contrast, the metal-based ionization bands of both bimetallic molecules show substantial broadening and splitting. Ionizations from the $\mathrm{d}_{\mathrm{xy}}-$ and $\mathrm{d}_{\mathrm{x}^{2}-\mathrm{y}^{2}}$-based orbitals are spread over a wide energy range, indicating delocalization across the two metal halves of the molecule and formal oxidation states of $+2 \frac{1}{2}$ for each metal atom in these cation species. The broadening and splitting of this ionization band for bis( $\mu$-fulvalenediyl)diiron is twice that observed for biferrocene. Ionizations from the $\mathrm{d}_{\mathrm{z}^{2}}$-based orbitals [using the traditional metal z-axis orientation toward the center of the ? ${ }^{5}$-Cp ring] occur in a single narrow band indicating both through-space and through-ligand interactions are not appreciable. The better energy match between the two-node empty Fv orbitals with metal $d_{x y}$-and $d_{x^{2}-y^{2}}$-based orbitals in bis $(\mu-$ fulvalenediyl)diiron than in biferrocene attributes to these difference on metal-metal interactions. In the gas phase, both species are considered as strongly interacting, delocalized mixed-valence compounds.

7. Characterization of the Electronic Structure of Transition Metal Carbonyls and Metallocenes, N.E. Gruhn and D.L. Lichtenberger, Inorganic Electronic Structure and Spectroscopy; Vol. II: Applications and Case Studies; Lever, A. B. P.; Solomon, E. I., Eds.; John Wiley and Sons: New York, 1999, pp 553-574.

During this period we published a review of the spectroscopy and theory directed toward understanding the electronic structure of transition metal carbonyls and metallocenes. The two most defining achievements of early organometallic chemistry were the discovery of transition metal carbonyl compounds and the synthesis of metallocenes. Over the last forty years compounds with carbonyl and cyclopentadienyl ligands have become ubiquitous throughout organometallic chemistry. In addition to the remarkable chemical and physical properties displayed by metal complexes that contain these ligands, the fascinating bonding modes of these ligands to metals have inspired new insights into electronic structure theories and new understanding of molecular structure and reactivity.

Understanding of the bonding and structure of metal carbonyls and metallocenes has continued to progress since the discovery of these classes of compounds, and is a wonderful illustration of the interplay of experiment and theory. This review compares and contrasts a variety of the most broad-based experimental and theoretical approaches to studying the fundamental bonding interactions in these molecules. With the large amount of work in this area over many years, completion of this review was a major accomplishment. One conclusion that became apparent is that the experimental results, computational methods and conceptual models have not yet reached a completely common ground for the description of these molecules. For example, different approaches present different views of the roles of carbonyl s donation and $\mathrm{p}$ acceptance, and call attention to other contributions to the metal-carbonyl bond. Fundamental points of continued focus for metal-carbonyls are the relative roles of carbonyl $\mathrm{s}$ and $\mathrm{p}$ bonding in both the ground and excited or ion states, the driving forces and synergism of the bonding, and the relevance of the frontier orbital model. The orbital model becomes an even greater concern for the metallocenes, both in terms of the relative energies of excited and ion states, and in terms of the fundamental bonding and geometrical structures of the molecules. Theoretical methods have had considerable difficulty in agreeing with even the most basic experimental results for metallocenes. The large amount of relaxation and correlation effects encountered in these systems have caused the calculation of experimental observables to be especially troublesome.

The observation of vibrational structure in spectroscopic studies of metal carbonyls provides unique insight into the bonding for these types of molecules. These results have proven to be some of the most direct experimental evidence for the applicability of the Dewar-Chatt-Duncanson bonding model. The electronic 
absorption spectra give information about the photo-excited states of metal-carbonyls, which is important for understanding their photoreactivity. The vibrational structure observed on the $t_{2 g}$ based ionizations of metal hexacarbonyls gives direct experimental observation of the structural influence of metal-to-carbonyl backbonding.

These are continuing areas of investigation. Improving experimental capabilities, and the development of computational approaches such as the density functional theories, promise interesting new developments in the future.

\section{Comparison of the Bonding of Benzene and $\mathrm{C}_{60}$ to a Metal Cluster: $\mathrm{Ru}_{3}(\mathrm{CO})_{9}\left(\mu^{3}-?^{2}, ?^{2}, ?^{2}-\mathrm{C}_{6} \mathrm{H}_{6}\right)$ and $\mathbf{R u}_{3}(\mathbf{C O})_{9}\left(\boldsymbol{\mu}^{3}-?^{2}, ?^{2}, ?^{2}-\mathbf{C}_{60}\right)$, M.A. Lynn and D.L. Lichtenberger, J. Cluster Sci. 2000, 11 (1), 169-188.}

No complexes have been shown previously to exhibit metal fragments bound symmetrically to a $\mathrm{C}_{6}$ face of a fullerene, which is surprising considering the many metal complexes containing ? $^{6}$ bound benzene and its derivatives. Shapley and coworkers have recently prepared $\mathrm{Ru}_{3}(\mathrm{CO})_{9}\left(\mu^{3}-?^{2}, ?^{2}, ?^{2}-\mathrm{C}_{60}\right)$, a molecular system that is analogous to the previously prepared and characterized hexahapto-ligated benzene system $\mathrm{Ru}_{3}(\mathrm{CO})_{9}\left(\mu^{3}-?^{2}, ?^{2}, ?^{2}-\mathrm{C}_{6} \mathrm{H}_{6}\right)$ as shown in the figure. The $\mathrm{Ru}_{3}$ core bonds symmetrically to a $\mathrm{C}_{6}$ face of $\mathrm{C}_{60}$ and, as the name implies, each metal atom is bound in a dihapto fashion. Fagan noted that the curvature of $\mathrm{C}_{60}$ forced the carbon $\mathrm{p}_{\mathrm{p}}$ atomic orbitals to tilt away from the center of the six-membered rings, an effect that would appear to weaken metal$\mathrm{C}_{60}$ orbital overlap for hexahapto bonding. Rogers and Marynick were the first to estimate by a computational method the

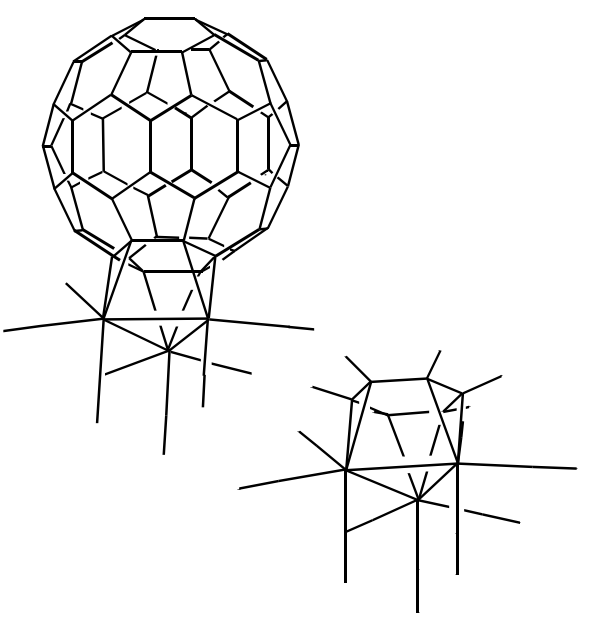
energetics of exchange of an $?^{6}$-bound benzene for $\mathrm{C}_{60}$. They determined that small metal atoms would indeed be more weakly bound to the fullerene than to $\mathrm{C}_{6} \mathrm{H}_{6}$ for the reason suggested by Fagan. Subsequently, Rogers and Marynick proposed that a large metal atom might be needed to form an ? ${ }^{6}$-bound $\mathrm{C}_{60}$ complex. Our calculations on a palladium atom with $\mathrm{C}_{60}$ did not indicate appreciable bonding at the $?^{6}$ position.

Considering the similarity in coordination between these benzene- and buckminsterfullerene-ligated systems, these molecules provided an opportunity to characterize this mode of bonding on a metal cluster. The electron distributions and bonding in $\mathrm{Ru}_{3}(\mathrm{CO})_{9}\left(\mu^{3}-?^{2}, ?^{2}, ?^{2}-\mathrm{C}_{6} \mathrm{H}_{6}\right)$ and $\mathrm{Ru}_{3}(\mathrm{CO})_{9}\left(\mu^{3}-?^{2}, ?^{2}, ?^{2}-\mathrm{C}_{60}\right)$ have been examined via electronic structure calculations. A fragment orbital approach, which is aided by the relatively high symmetry that these molecules possess, reveals important features of the electronic structures of these two systems. Reported crystal structures show that both benzene and $\mathrm{C}_{60}$ are geometrically distorted when bound to the metal cluster fragment, and our $a b$ initio calculations indicate that the energies of these distortions are similar. The experimental $\mathrm{Ru}-\mathrm{C}_{\text {fullerene }}$ bond lengths are shorter than the corresponding $\mathrm{Ru}-\mathrm{C}_{\text {benzene }}$ distances and the $\mathrm{Ru}-\mathrm{Ru}$ bond lengths are longer in the fullerene-bound cluster than for the benzene-ligated cluster. Also, the carbonyl stretching frequencies are slightly higher for for $\mathrm{Ru}_{3}(\mathrm{CO})_{9}\left(\mu^{3}-?^{2}, ?^{2}, ?^{2}-\mathrm{C}_{60}\right)$ than for $\mathrm{Ru}_{3}(\mathrm{CO})_{9}\left(\mu^{3}-\right.$ $\left.?^{2}, ?^{2}, ?^{2}-\mathrm{C}_{6} \mathrm{H}_{6}\right)$. As a whole, these observations suggest that electron density is being pulled away from the metal centers and $\mathrm{CO}$ ligands to form stronger $\mathrm{Ru}-\mathrm{C}_{\text {fullerene }}$ than $\mathrm{Ru}-\mathrm{C}_{\text {benzene }}$ bonds. Fenske-Hall molecular orbital calculations show that an important interaction is donation of electron density in the metal-metal bonds to empty orbitals of $\mathrm{C}_{60}$ and $\mathrm{C}_{6} \mathrm{H}_{6}$. Bonds to the metal cluster that result from this interaction are the second highest occupied orbitals of both systems. A larger amount of density is donated to $\mathrm{C}_{60}$ than to $\mathrm{C}_{6} \mathrm{H}_{6}$, thus accounting for the longer metal-metal bonds in the fullerene-bound cluster. The principal metal-arene bonding modes are the same in both systems, but the more band-like electronic structure of the fullerene (i.e., the greater 
number density of donor and acceptor orbitals in a given energy region) as compared to $\mathrm{C}_{6} \mathrm{H}_{6}$ permits a greater degree of electron flow and stronger bonding between the $\mathrm{Ru}_{3}(\mathrm{CO})_{9}$ and $\mathrm{C}_{60}$ fragments. Of significance to the reduction chemistry of $\mathrm{M}_{3}(\mathrm{CO})_{9}\left(\mu^{3}-?^{2}, ?^{2}, ?^{2}-\mathrm{C}_{60}\right)$ molecules, the HOMO is largely localized on the metalcarbonyl fragment and the LUMO is largely localized on the $\mathrm{C}_{60}$ portion of the molecule. The localized $\mathrm{C}_{60}$ character of the LUMO is consistent with the similarity of the first two reductions of this class of molecules to the first two reductions of free $\mathrm{C}_{60}$. The set of orbitals above the LUMO shows partial delocalization (in an antibonding sense) to the metal fragment, thus accounting for the relative ease of the third reduction of this class of molecules compared to the third reduction of free $\mathrm{C}_{60}$.

9. Ligand Effects on Metal-Metal Interactions: The Relationship Between Rh-Rh Bonding and Catalytic Selectivity of $\mathbf{d}^{7}-\mathbf{d}^{7} \mathbf{R} \mathbf{h}_{2}$ Complexes. Pollard, J. R. "Ligand Effects and Periodic Trends in Metal-Metal Multiple Bonds: Theoretical and Experimental Studies of Electronic Structure by Gas-Phase Photoelectron Spectroscopy"; Ph.D. Dissertation. Diss. Abstr. Int. B 1997, 58 (2), 695; 1997: The University the Arizona; 172 pp.(DOE)

$\mathrm{Rh}_{2} \mathrm{~L}_{4}$ (where $\mathrm{L}=\mathrm{O}_{2} \mathrm{CCF}_{3}, \mathrm{O}_{2} \mathrm{CCF}_{2} \mathrm{CR}_{2} \mathrm{CF}_{3}$, OCO-n- $\mathrm{C}_{8} \mathrm{H}_{17}, \mathrm{~N}\left(\mathrm{C}_{6} \mathrm{H}_{6}\right) \mathrm{OCH}_{3}, \mathrm{~N}\left(\mathrm{C}_{6} \mathrm{~F}_{6}\right) \mathrm{OCH}_{3}$, $(\mathrm{Nph})_{2} \mathrm{CH}$ and caprolactamate) systems exhibit extremely selective catalytic properties in a variety of examples. Ligand substitution on the $\mathrm{Rh}_{2}$ moiety can drastically alter the selectivity of the catalyst. The figure at the right show that for the dirhodium system the caprolactamate ligand (bottom) leads with $100 \%$ selectivity to cyclopropanation, whereas the perfluorocarboxylate ligand (top) leads to $100 \%$ $\mathrm{C}-\mathrm{H}$ insertion prducts. Both reactions are expected to occur at the axial position of the metal-metal bond. In order to study the relationship between electronic structure and ligand substitution, gas-phase photoelectron spectra of all the above mentioned $\mathrm{Rh}_{2} \mathrm{~L}_{4}$ systems have been collected in order to determine the electron configuration of the $\mathrm{Rh}-\mathrm{Rh}$ interaction, and study specifically how ligands shift these levels, and hence direct catalytic selectivity. Experimental results support a formal electron

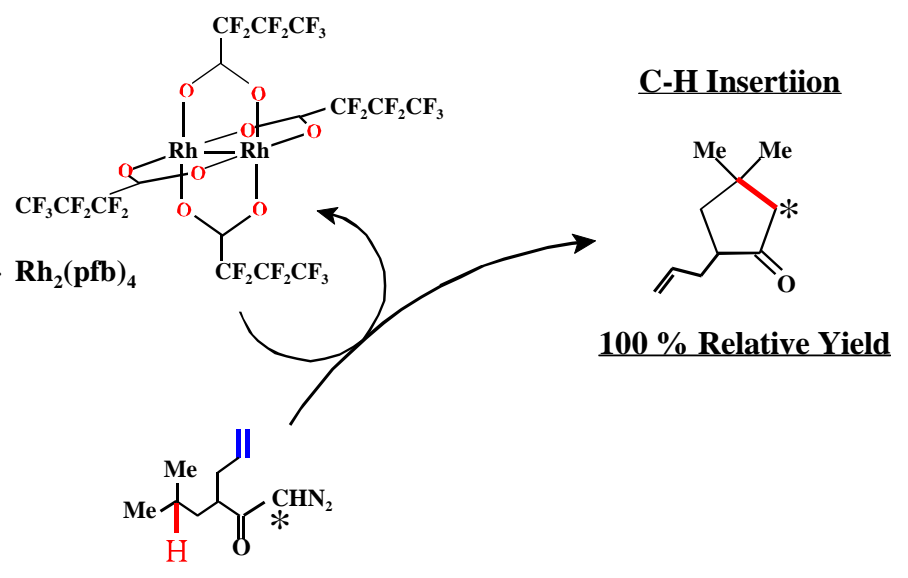
configuration of $\mathrm{s}^{2} \mathrm{p}^{4} \mathrm{~d}^{2} \mathrm{~d}^{* 2} \mathrm{p}^{* 2}$ between the metals in these systems. The primary difference is found to be in the electron richness at the metal centers, which is much greater in the bottom molecule. Ligands which stabilize the $\mathrm{d}^{*}$ favor carbene insertions into $\mathrm{C}-\mathrm{H}$ bonds, while ligands which destabilize the $\mathrm{d}^{*}$ favor carbene cyclopropanations with olefins. The implications of this electron richness to this reactivity are still under investigation.

10. Preparation, Characterization and Electronic Structure of $\mathrm{W}_{2}\left(\mathrm{NMe}_{2}\right)_{2}\left(\mathrm{OR}_{\mathrm{f}}\right)_{4}, W$ here $\mathrm{R}_{\mathrm{f}}=\mathrm{CMe}_{2} \mathrm{CF}_{3}$, $\mathrm{CMe}\left(\mathrm{CF}_{3}\right)_{2}$, and $\mathrm{C}\left(\mathrm{CF}_{3}\right)_{3}$ as Deduced by Photoelectron Spectroscopic Studies and the Single Crystal X-ray Structure for $\mathbf{R}_{\mathrm{f}}=\mathbf{O C M e}\left(\mathbf{C F}_{3}\right)_{2}$. T.A. Budzichowski, M.H. Chisholm, D.B. Tiedtke, N. Gruhn, and D.L. Lichtenberger, Polyhedron 1998, 17(5-6), 705-711. 
The reactivity of metal centers in the title molecules is greatly influenced by the nature of the metal, its electronic configuration, and its environment of ligands. For instance, $\mathrm{W}_{2}\left(\mathrm{O}^{t} \mathrm{Bu}\right)_{6}$ causes a reductive cleavage of nitriles, while $\mathrm{Mo}_{2}\left(\mathrm{O}^{t} \mathrm{Bu}\right)_{6}$ is inert under similar conditions. However, changing the ligand from $\mathrm{O}^{t} \mathrm{Bu}$ to $\mathrm{OCMe}_{2} \mathrm{CF}_{3}$ results instead in a reversible Lewis base association. Similar change in the reactivity occur with $\mathrm{NMe}_{2}$ ligands.

The compounds $\mathrm{W}_{2}\left(\mathrm{NMe}_{2}\right)_{2}\left(\mathrm{OCMe}_{2} \mathrm{CF}_{3}\right)_{4}, \mathbf{1}, \mathrm{W}_{2}\left(\mathrm{NMe}_{2}\right)_{2}\left(\mathrm{OCMe}\left(\mathrm{CF}_{3}\right)_{2}\right)_{4}, \mathbf{2}$, and $\mathrm{W}_{2}\left(\mathrm{NMe}_{2}\left(\mathrm{OC}\left(\mathrm{CF}_{3}\right)_{3}\right)_{4}\right.$, 3 , have been obtained from reactions between $\mathrm{W}_{2}\left(\mathrm{NMe}_{2}\right)_{6}$ and the respective fluoroalcohol in hydrocarbon solvents. The compounds $\mathbf{2}$ and $\mathbf{3}$ appear inert to further reaction with their fluoroalcohol at room temperature while 1 reacts further to give $\mathrm{W}_{2}\left(\mathrm{OCMe}_{2} \mathrm{CF}_{3}\right)_{6}$. In solution, NMR data indicate that all three compounds exist in a mixture of anti- and gauche-rotamers with restricted rotations about both $\mathrm{W}-\mathrm{N}$ and $\mathrm{W} / \mathrm{W}$ bonds on the NMR time-scale. The solid-state molecular structure of $\mathbf{2}$ reveals a centrosymmetric $\mathrm{NO}_{2} \mathrm{~W} / \mathrm{WO} \mathrm{N}_{2}$ core with $\mathrm{W}-\mathrm{W}=2.3107(6) \AA, \mathrm{W}-\mathrm{N}=1.914(4) \AA, \mathrm{W}-\mathrm{O}=1, .959(3)$ and 1.907(3) $\AA$ and angles $\mathrm{W}-\mathrm{W}-\mathrm{O} / \mathrm{N}$ within the range 100 to $110^{\circ}$. The gas-phase photoelectron spectra for $\mathbf{1}, \mathbf{2}$ and $\mathbf{3}$ were obtained and compared with that previously reported for $\mathrm{W}_{2}\left(\mathrm{NMe}_{2}\right)_{6}$. The introduction of the fluoroalkoxide ligands has a pronounced effect in stabilizing the metal and nitrogen lone-pair based ionizations, and this effect is amplified by the successive replacement of each methyl group by a trifluoromethyl group. Also, for the compounds $\mathbf{1}, \mathbf{2}$ and $\mathbf{3}$ the lowest ionization bands clearly reveal the removal of the degeneracy of the W-W p MO's as expected for anti and gauche complexes.

\section{B. Dissertations and Theses Abstracts:}

1. Synthesis and Characterization of Metal-Acetylide Complexes, Wu, T. S.-C., Honors B. S. Thesis: The University of Arizona, 1998.

The metal-acetylide complexes $\mathrm{M}_{2}\left(\mathrm{PMe}_{3}\right)_{4} \mathrm{X}_{4}\left(\mathrm{M}=\mathrm{Mo} ; \mathrm{X}=\mathrm{C} / \mathrm{C}-\mathrm{SiMe}_{3}, \mathrm{C} / \mathrm{C}-{ }^{\mathrm{t}} \mathrm{Bu}, \mathrm{Cl}\right.$ and $\mathrm{M}=\mathrm{Re} ; \mathrm{X}$ $\left.=\mathrm{C} / \mathrm{C}-\mathrm{SiMe}_{3}, \mathrm{Cl}\right)$ and $\left(?^{5}-\mathrm{C}_{5} \mathrm{H}_{5}\right) \mathrm{Fe}(\mathrm{CO})_{2} \mathrm{C} / \mathrm{C}-\mathrm{SiMe}_{3}$ were synthesized and characterized by gas-phase photoelectron spectroscopy to experimentally measure their ionization energies. The bonding interactions of the metal-metal core in $\mathrm{M}_{2}\left(\mathrm{PMe}_{3}\right)_{4} \mathrm{X}_{4}$ are well characterized providing an infrastructure for experimental modification. To tune electron richness, the metal was varied to populate the $\mathrm{d}$ and $\mathrm{d}^{*}$ orbitals, and the effects on bonding with the acetylidep and $\mathrm{p}^{*}$ orbitals were observed. The $\left(?^{5}-\mathrm{C}_{5} \mathrm{H}_{5}\right) \mathrm{Fe}(\mathrm{CO})_{2}$ fragment of Fp-acetylide complexes is also well characterized, and can be used as a template for comparison. The effects of silicon substitution were observed on the acetylenes and metal-acetylides, and compared to previously characterized compounds. Gas-phase He I and He II photoelectron spectroscopy depicted a stabilization of ionization potentials with silicon substitution. This data indicates that the $\mathrm{Si}$ atom facilitates delocalization of the electron distribution.

\section{Photoelectron Spectroscopy and Computational Studies of Electron Delocalization in Organometallic Complexes, Fan, H.-J., Ph.D. Dissertation: The University of Arizona, 1999.}

Metal-metal and metal-ligand electron delocalization in organometallic complexes, such as biferrocene, bis( $\mu$-fulvalenediyl)diiron, $\quad \mathrm{CpM}(\mathrm{CO})_{4}, \quad(\mathrm{Cn} *) \mathrm{RhMe}_{3}, \quad$ and $\quad\left(\mathrm{P}_{3}\right) \mathrm{RhMe}_{3}, \quad(\mathrm{Cn} *=1,4,7$-trimethyl-1,4,7triazacyclononane and $\mathrm{P}_{3}=\mathrm{CH}_{3} \mathrm{C}\left(\mathrm{CH}_{2} \mathrm{PMe}_{2}\right)_{3}$ are examined by gas-phase photoelectron spectroscopy. Theoretical studies at various computational levels are also carried out to understand the delocalization.

The metal-metal electron delocalization is studied using biferrocene and bis( $\mu$-fulvalenediyl)diiron molecules. Compared with monometallic molecules, these molecules show a different degree of electron delocalization through a bridging ligand depending on the energy match between each ferrocene fragment. The extended $\mathrm{p}$ system of the ligand has greater impact on the ligand-based ionizations than on the metal-based 
ionizations. The tilted $\mathrm{Cp}$ ring affects the metal-based band profile of ferrocene and contributes to the shortened Fe-Fe distance in the bis ( $\mu$-fulvalenediyl)diiron cation. Further splitting and broadening of the metalbased ionization band is observed for the ring-tilted ferrocene.

The metal-ligand electron delocalization is studied with two type of molecules. The first is (? ${ }^{5}$ $\left.\mathrm{C}_{5} \mathrm{H}_{4} \mathrm{R}\right) \mathrm{M}(\mathrm{CO})_{4}\left(\mathrm{R}=\mathrm{H}, \mathrm{M}=\mathrm{V}, \mathrm{Nb}, \mathrm{Ta} ; \mathrm{R}=\mathrm{SiMe}_{3}, \mathrm{M}=\mathrm{Nb}, \mathrm{Ta} ; \mathrm{R}=\mathrm{COCH}_{3}, \mathrm{M}=\mathrm{Nb}\right)$ which is used to probe the metal-carbonyl interaction. In general, these molecules exhibit both extensive delocalization of metal electron density and geometric sensitivity to the electron configuration. Such strong delocalization dampens the substitutent effect introduced onto the $\mathrm{Cp}$ ring or at the metal center. A consistent splitting of $0.4 \mathrm{eV}$ is observed for the Cp-based ionization band for all of the molecules due to a dynamic Jahn-Teller distortion of the positive ions.

The other type of molecule is $(\mathrm{L}) \mathrm{RhMe}_{3}\left[\mathrm{~L}=\mathrm{Cn}^{*}\right.$ and $\left.\mathrm{P}_{3}\right]$. The amine molecule exhibits a negligible backbonding from the metal to the ligand while the phosphine molecule shows a strong metal-phosphine interaction provided by the electron donation from the metal to the phosphines. As a comparison, spectra of ligands $\mathrm{Cn}^{*}, \mathrm{Cn}$, and $\mathrm{P}_{3}$ show a similar band profile for the first ionization band. Theoretical studies demonstrate that the metal-phosphine backbonding accounts for the different band profiles in photoelectron spectra.

A theoretical study of the relaxation energy of metal-based ionizations of $\mathrm{CpM}(\mathrm{CO})_{\mathrm{n}}(\mathrm{M}=\mathrm{V}, \mathrm{Nb}, \mathrm{Ta}, \mathrm{n}=4$; $\mathrm{M}=\mathrm{Mn}, \mathrm{Tc}, \mathrm{Re}, \mathrm{n}=3 ; \mathrm{M}=\mathrm{Co}, \mathrm{Rh}, \mathrm{Ir}, \mathrm{n}=2$ ) in the Hartree-Fock formalism has been carried out. The results show that the electron relaxation energy of these molecules can be well understood in terms of Slater's concepts of electron shielding and effective nuclear charge.

\section{Metal, Ligand, and Symmetry Influences on Metal-Metal Bonds: Photoelectron Spectroscopy and Theory. Lynn, M. A., Ph. D. Dissertation: The University of Arizona, 2000.}

Three sets of metal-metal bonded systems of the form $\mathrm{M}_{2}\left(\mathrm{~L}\{\mathrm{~L})_{4}\right.$ have been studied by gas-phase ultraviolet photoelectron spectroscopy and electronic structure calculations to understand the electronic structures of and bonding in these molecules. The ligand sets range from the relatively poor electron donor trifluoroacetate ligand, to hydroxymethylpyridinate (mhp), and finally to the relatively strong electron donor N,NN diphenylformamidinate (form) ligand. Not only does this study elucidate the methods by which metal and ligand interact throughout a series of differing electron donor ligand sets, but it also presents a cohesive understanding of the electronic structures of these systems in terms of overall molecular symmetry. In particular, the relative stabilities and orbital characters of the metal-metal bonding and antibonding orbitals are probed to understand the ability of a particular ligand set to affect the ability of two metal atoms to bind together.

First, compounds of the form $\mathrm{M}_{2}(\text { form })_{4}(\mathrm{M}=\mathrm{Cr}, \mathrm{Mo}, \mathrm{W}, \mathrm{Ru}, \mathrm{Rh}, \mathrm{Pd})$ are examined. The spectra of the metal-metal quadruple bond-containing systems (i.e., $\mathrm{M}_{2}(\text { form })_{4}$ where $\mathrm{M}=\mathrm{Cr}, \mathrm{Mo}, \mathrm{W}$ ) are used to identify several metal- and ligand-based ionization features, which can then be used to identify the additional metalbased features in the spectra of the remaining systems. Given the ease with which functional groups can be added to the formamidinate ligand, a series of substituted $\mathrm{Mo}_{2}(\text { form })_{4}$ systems have been prepared and their ionization data have been compared with solution-phase electrochemical results.

Next, the electronic structures of $\mathrm{M}_{2}\left(\mathrm{O}_{2} \mathrm{CCF}_{3}\right)_{4}(\mathrm{M}=\mathrm{Mo}, \mathrm{Rh})$ are studied. Variable energy photon experiments reveal a predominance of ligand character in the M-M s and p orbitals, despite the relatively poor overall electron donor ability of the ligand. The means by which such a ligand can interact by symmetry with these metal orbitals are studied by computational methods. 
Finally, the bonding in $\mathrm{M}_{2}(\mathrm{mhp})_{4}(\mathrm{M}=\mathrm{Cr}, \mathrm{Mo}, \mathrm{W}, \mathrm{Ru}, \mathrm{Rh})$ systems is probed. The lower symmetry of these molecules and the intermediate donor properties of this ligand set allow for correlation with the electronic structures of $\mathrm{M}_{2}$ (form $)_{4}$ and $\mathrm{M}_{2}\left(\mathrm{O}_{2} \mathrm{CCF}_{3}\right)_{4}$. Unlike for the higher symmetry systems, ligand involvement in the $\mathrm{M}-\mathrm{M} \mathrm{d}$ bond is observed and can be understood in terms of molecular symmetry arguments.

\section{Other Preliminary Results}

1. Electronic Structure and Relative $\mathrm{Fe}-\mathrm{H}$ and $\mathrm{Fe}-\mathrm{CH}_{3}$ Bond Dissociation Energies of $\left(?^{5}-\mathrm{C}_{5} \mathrm{R}_{5}\right) \mathrm{Fe}(\mathrm{CO})_{2} \mathrm{R}$ Compounds $\left(\mathrm{R}=\mathrm{H}\right.$ or $\left.\mathrm{CH}_{3}\right)$ from Photoelectron Spectroscopy. D. L. Lichtenberger and S. K. Renshaw, (with R. M. Bullock, Chemistry Department, Brookhaven National Laboratory). (DOE)

The bonding of hydride and methyl ligands in transition-metal compounds is an important aspect of catalysis and reactivity in organometallic chemistry. The electronic structure and bonding of $\mathrm{FpH}, \mathrm{FpCH}_{3}$, Fp*H and $\mathrm{Fp}^{*} \mathrm{CH}_{3}$ compounds ( where $\mathrm{Fp}=\left(?^{5}-\mathrm{C}_{5} \mathrm{H}_{5}\right) \mathrm{Fe}(\mathrm{CO})_{2}$ and $\left.\mathrm{Fp}^{*}=\left(?^{5}-\mathrm{C}_{5} \mathrm{Me} 5\right) \mathrm{Fe}(\mathrm{CO})_{2}\right)$ are investigated using gas-phase $\mathrm{He} \mathrm{I}$ photoelectron spectroscopy. The $\mathrm{FpH}$ compound serves as a excellent comparison for previously studied FpR compounds, where $\mathrm{R}$ is $\mathrm{CH}_{3}, \mathrm{Cl}, \mathrm{Br}, \mathrm{I}, \mathrm{SiR}_{3}$ and $\mathrm{CN}$. The photoelectron spectra contain ionization bands that originate from the Fe(II) $\mathrm{d}^{6}$ metal center, the cyclopentadienyl ring $\mathrm{p}$ system and the metal-ligand sigma bond. Trends in the spectra and Fenske-Hall calculations show mixing between Cp ring e set orbitals and the Fe-R sigma bond orbital, both of which utilize the " $e_{g}$ " derived metal d orbitals in the pseudo-octahedral environment. Thus, the electron density in the metal-ligand bond is delocalized through the molecule. The thermodynamic relationship between the ionization energy and bond dissociation energy (BDE) allows us to estimate the difference in metal-carbon and metal-hydride BDE for these bonds in FpR and Fp*R compounds. From the $\mathrm{Fe}-\mathrm{H}$ and $\mathrm{Fe}-\mathrm{C}$ sigma bond ionizations, we estimate that the $\mathrm{M}-\mathrm{H}$ bond is $20 \pm 2$ $\mathrm{kcal} / \mathrm{mol}$ more stable than the $\mathrm{M}-\mathrm{CH}_{3}$ bond in $\mathrm{FpR}$ compounds. The uncertainty in the relative bond strengths is partly due to mixing of the metal-Cp and metal-ligand bonds.

2. Electronic Interactions in $\mathrm{CpRe}(\mathrm{NO})(\mathrm{L}) \mathrm{R}$ Complexes $\left[\mathrm{Cp}=?^{5}-\mathrm{C}_{5} \mathrm{H}_{5}, ?^{5}-\mathrm{C}_{5}\left(\mathrm{CH}_{3}\right)_{5} ; \mathrm{L}=\mathrm{CO}, \mathrm{P}\left(\mathrm{C}_{6} \mathrm{H}_{5}\right)_{3} ; \mathrm{R}=\mathrm{H}\right.$, $\mathrm{CH}_{3}$ )]: Comparison of $\mathrm{Re}-\mathrm{H}$ Bond Ionizations with Re$\mathrm{CH}_{3}$ Bond Ionizations. D. L. Lichtenberger, N. E. Gruhn, A. Rai-Chaudhuri, and S. K. Renshaw (with J. A. Gladysz (Univ Erlangen Nurnberg), J. Seyler and A. Igau) (DOE)

We have extended our work on the hydride and methyl complexes of the $\mathrm{Fp}$ fragment to the $\mathrm{CpRe}(\mathrm{NO})(\mathrm{CO})^{+}$ fragment, which is isoelectronic with Fp. Comparison of the PES of the Re-hydride and methyl compounds shows that the methyl ligand is acting as a p donor in these complexes. This comparison also shows mixing between the $\mathrm{Cp}$ and $\mathrm{s}(\mathrm{Re}-\mathrm{R})$ levels and suggests a delocalized sigma bonding framework.

Perhaps the most interesting observation from this study is that the $\mathrm{Cp} * \operatorname{Re}(\mathrm{NO})(\mathrm{CO}) \mathrm{H}$ and $\mathrm{CpRe}(\mathrm{NO})(\mathrm{CO}) \mathrm{H}$ photoelectron spectra show, for the first time, vibrational fine structure on a metal-ligand sigma bond ionization. A close-up spectrum of the $\mathrm{s}(\mathrm{Re}-\mathrm{H})$ ionization of $\mathrm{Cp} * \mathrm{Re}(\mathrm{NO})(\mathrm{CO}) \mathrm{H}$ is

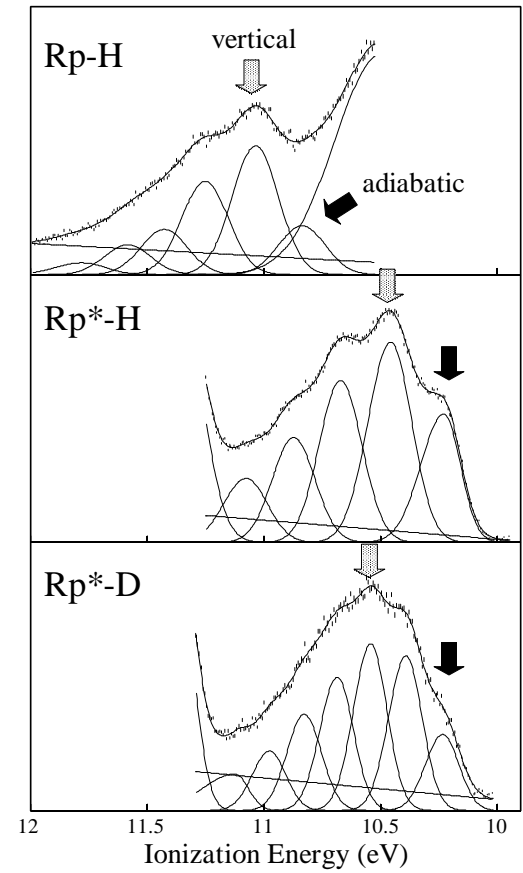

Vibrational structure on Re-H and Re-D s -bond ionizations. 
shown in Figure 5. The discrete shoulders on the band are easily modeled with symmetric Gaussian bands. The peak at $10.23 \mathrm{eV}$ is the adiabatic ionization. The most intense peak in the ionization envelope, at 10.46 $\mathrm{eV}$, corresponds to the vertical ionization. In this case, the vertical ionization potential corresponds to the ? to $?_{1}$ (cation) transition.

To confirm that the vibrational progression on the $\mathrm{s}(\mathrm{Re}-\mathrm{H})$ band was actually due to the Re-H bond vibration, the spectrum of the deuterated analog, $\mathrm{Cp} * \operatorname{Re}(\mathrm{NO})(\mathrm{CO}) \mathrm{D}$, has been obtained. The valence region spectrum of $\mathrm{Cp} * \operatorname{Re}(\mathrm{NO})(\mathrm{CO}) \mathrm{D}$ was identical to the hydride analog with one exception, the shape of the $\mathrm{s}(\operatorname{Re}-$ D) ionization band. A close-up of the $s(\mathrm{Re}-\mathrm{D})$ in the figure shows the different shape of the ionization. Modeling with Gaussian peaks places the adiabatic ionization at $10.24 \mathrm{eV}$, which is statistically the same as that for the hydride analog, and the vertical ionization corresponds to the transition from the $?_{0}$ to the ? ${ }_{2}$ (cation) level in the molecule.

In the $\mathrm{Cp} * \mathrm{Re}(\mathrm{NO})(\mathrm{CO}) \mathrm{H}$ compounds, the ionic ?(Re-H) is $0.215 \mathrm{eV} \pm 0.010 \mathrm{eV}\left(1730 \pm 80 \mathrm{~cm}^{-1}\right)$, which is slightly lower than the Re-H bond frequency in the neutral molecule, $1994 \mathrm{~cm}^{-1}(\mathrm{KBr})$. The decrease in frequency is direct evidence for the bonding nature of the $\mathrm{Re}-\mathrm{H}$ orbital. For the $\mathrm{Cp} * \operatorname{Re}(\mathrm{NO})(\mathrm{CO}) \mathrm{D}$ compound the ionic ?(Re-D) is $0.150 \pm 0.010 \mathrm{eV}\left(1200 \pm 80 \mathrm{~cm}^{-1}\right)$, which again is lower than the ?(Re-D) value in the neutral molecule $\left(1453 \mathrm{~cm}^{-1}, \mathrm{KBr}\right)$ and also is exactly as predicted by the reduced mass effect. The difference between the ionic and molecular frequencies for the isotopomers is the same within experimental error.

The close-up spectrum of the $\mathrm{s}(\mathrm{Re}-\mathrm{H})$ ionization of $\mathrm{CpRe}(\mathrm{NO})(\mathrm{CO}) \mathrm{H}$ is also shown in the figure. The position of the adiabatic ionization is uncertain because the $\mathrm{Cp}$ ionization band overlaps with the low binding energy side of the $\mathrm{s}(\mathrm{Re}-\mathrm{H})$ band. The vertical ionization energy, at $11.03 \mathrm{eV}$, is more certain. The vibrational progression has a frequency of $1890 \pm 160 \mathrm{~cm}^{-1}$, which is slightly smaller than the ?(Re-H) for the neutral molecule, which is $2013 \mathrm{~cm}^{-1}$ (Raman, neat).

Using the vibrational information from the spectra, we can estimate the change in bond distance when an electron is removed from a bond. The vibrational frequency of the ion (?') is related to the difference in equilibrium bond distance between the ion and molecule (d) by the expression shown in the equation, where $?_{\max }$ is the vibrational quantum number at the maximum intensity, and $\mathrm{F}$ is the reduced mass appropriate for the vibration. For $\mathrm{CpRe}(\mathrm{NO})(\mathrm{CO}) \mathrm{H}$ with $?_{\max }=1$, Equation 2 can be used to calculate that the Re-H bond lengthens by $0.23 \pm 0.07 \AA$ upon removal of an electron. Similar calculation of $\mathrm{d}$ for $\mathrm{Cp} * \operatorname{Re}(\mathrm{NO})(\mathrm{CO}) \mathrm{H}$ and $\mathrm{Cp} * \operatorname{Re}(\mathrm{NO})(\mathrm{CO}) \mathrm{D}$ gives values of $0.24 \pm 0.05 \AA$ and $0.27 \pm 0.05 \AA$, respectively.

This research area will continue with the investigation of other transition metal complexes containing M$\mathrm{CH}_{3}$ and $\mathrm{M}-\mathrm{H}$ bonds. It is quite possible that vibrational fine structure not previously resolved could now be observed for hydride complexes that have previously had PES reported, such as $\mathrm{Cp} * \mathrm{Fe}(\mathrm{CO})_{2} \mathrm{H}$ and $(\mathrm{CO})_{5} \mathrm{ReH}$. We have begun reinvestigation of the PES of these complexes, which will give valuable information about the strength of transition metal-hydride bonds.

3. Oxidative Addition to Rhodium and Iridium Complexes. (DOE) 
Oxidative addition is an important elementary process in reaction mechanisms involving transition metal catalysts, including Vaska's Complex and Wilkinson's catalyst The most interesting and relevant systems to this project are those compounds that are products of alkane $\mathrm{C}-\mathrm{H}$ oxidative addition. Bergman, et. al. showed that photolysis of the $\mathrm{Cp} * \mathrm{Ir}\left(\mathrm{PMe}_{3}\right) \mathrm{H}_{2}$ compound in alkane solvent gives stable alkyl hydride products,

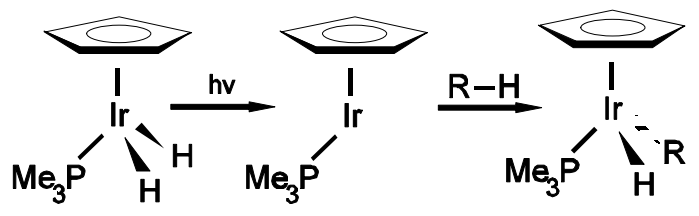

Alkane C-H Activation By Cp*M(PMe $)_{3}(\mathrm{H})_{2}$

$\mathrm{Cp} * \operatorname{Ir}\left(\mathrm{PMe}_{3}\right)(\mathrm{R})(\mathrm{H})$, as shown. This intermolecular oxidative addition is very general and has activated C-H bonds of both unstrained (methane, cyclohexane) and strained (cubane, adamantane) alkanes to give isolable products. The rhodium analog $\mathrm{Cp} * \mathrm{Rh}\left(\mathrm{PMe}_{3}\right)(\mathrm{H})_{2}$ also activates $\mathrm{C}-\mathrm{H}$ bonds of methane and arenes, but reductive elimination occurs at about $120 \mathrm{EC}$ below the iridium analogs. Kinetic and thermodynamic experiments show that the driving force appears to be strong metal-carbon and metal-hydrogen bonds. This suggests that a unique electronic structure is present. Replacement of the $\mathrm{Cp}^{*}$ by $\mathrm{Cp}$ in the rhodium complex was found to have a significant effect when the complex was reacted with fused polycycles. The oxidative addition product was favored in the $\mathrm{Cp}^{*}$ complex, while $?^{2}$-arene product was favored with the Cp complex. Variation of the phosphine in $\mathrm{Cp} * \mathrm{Rh}\left(\mathrm{PR}_{3}\right)(\mathrm{H})(\mathrm{Ph})$ also leads to different stabilities of the aryl hydride (as measured by benzene reductive elimination), an effect that cannot be explained by steric effects alone. The different reactivities of these complexes suggest that changing the electron density at the metal center affects the reactivity of the fragment and the stability of the alkyl hydride.

Previously we have published work on the valence and core ionizations and electronic structure of $\left(?^{5}-\mathrm{C}_{5} \mathrm{H}_{5}\right) \mathrm{M}(\mathrm{CO})_{2}$ and $\left(?^{5}-\right.$ $\left.\mathrm{C}_{5} \mathrm{Me}_{5}\right) \mathrm{M}(\mathrm{CO})_{2}$ complexes $(\mathrm{M}=\mathrm{Co}, \mathrm{Rh})$. This study established the basic electronic structure for $\mathrm{d}^{8} \mathrm{CpRh}(\mathrm{CO})_{2}$ complexes. Our preliminary studies have centered on compounds of the type $\mathrm{Cp} * \mathrm{Rh}\left(\mathrm{PMe}_{3}\right)(\mathrm{R})_{2}$, where $\mathrm{R}$ is $\mathrm{H}$ or $\mathrm{CH}_{3}$. The isolobal analogy, which usually is a good qualitative indicator of orbital interactions, would predict that the compounds be isolobal to $\mathrm{CpMn}(\mathrm{CO})_{3}$. The $\mathrm{PE}$ spectrum of the $\mathrm{Cp} * \mathrm{Rh}\left(\mathrm{PMe}_{3}\right)(\mathrm{Me})_{2}$ compound shows very different electronic structure. The HeI and He II spectra of the valence region ( 7 to $11 \mathrm{eV}$ ) of $\mathrm{Cp} * \mathrm{Rh}\left(\mathrm{PMe}_{3}\right)\left(\mathrm{CH}_{3}\right)_{2}$ is shown in the figure. We seeing two surprises in the $\mathrm{Cp} * \mathrm{Rh}\left(\mathrm{PMe}_{3}\right)(\mathrm{Me})_{2}$ spectra. First, the metal based ionizations, labeled A, B and C, are split by $0.80 \mathrm{eV}$, showing clearly nondegenerate metal based orbitals. Second, the HeII data shows that the HOMO (A) and SHOMO (B) based ionizations are approximately $50 \%$ ligand based. Likewise, the D and $\mathrm{E}$ ionizations, which would normally be assigned to the $\mathrm{Cp}$ ring ionizations, are approximately $50 \%$ metal in character.

This data suggests that there is a rehybridization at the metal center, so that the $\mathrm{Cp}^{*}$ ring orbitals have a filled/filled interaction with two of the metal orbitals. The A and B ionizations correspond to the antibonding combination and have been destabilized as a result of this

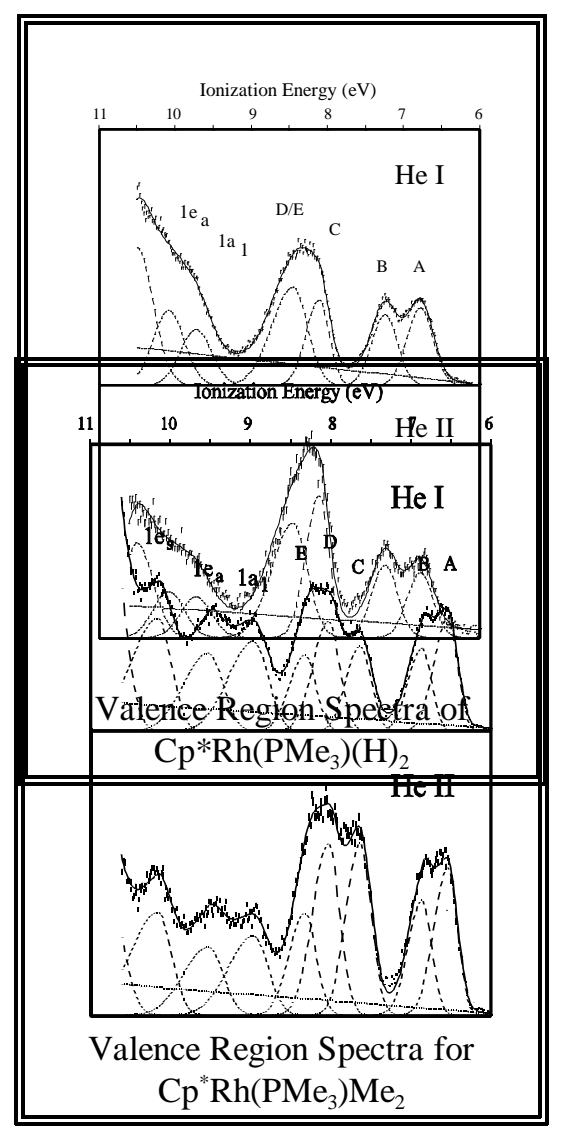


interaction. Likewise, the $\mathrm{D}$ and $\mathrm{E}$ ionizations correspond to the bonding combination. Fenske-Hall molecular orbital calculations support this bonding picture, and also suggest that the metal-carbon bonds are also mixed into the HOMO and SHOMO. The destabilization and change in character of these ionizations will have a strong effect on the reactivity. More sophisticated calculations are called for.

The HeI and HeII spectra of $\mathrm{Cp} * \mathrm{Rh}\left(\mathrm{PMe}_{3}\right) \mathrm{H}_{2}$ show an electronic structure similar to that of $\mathrm{Cp} * \mathrm{Rh}\left(\mathrm{PMe}_{3}\right)(\mathrm{Me})_{2}$. The first two ionizations are analogous to the $\mathrm{A}$ and $\mathrm{B}$ orbitals in the $\mathrm{Cp} * \mathrm{Rh}\left(\mathrm{PMe}_{3}\right)(\mathrm{Me})_{2}$ spectra, except that now they shrink by $40 \%$ and $50 \%$ (relative to the $\mathrm{C}$ ionization) in the He II spectra. The electronic structure is analogous to $\mathrm{Cp} * \mathrm{Rh}\left(\mathrm{PMe}_{3}\right)(\mathrm{Me})_{2}$, with one important difference, the HOMO and SHOMO based ionizations are now primarily ligand based.

The mixing of ligand based orbitals into the normally nonbonding metal $t_{2 g}$ set is atypical, but not unknown. A survey of the literature found two examples. In the PE spectrum of $\mathrm{Cp} * \operatorname{Ir}(\mathrm{DMSO}) \mathrm{Me}_{2}$, the first three ionization bands have an analogous splitting pattern to those observed in $\mathrm{Cp} * \mathrm{Rh}\left(\mathrm{PMe}_{3}\right) \mathrm{Me}_{2} . \mathrm{Cp} * \mathrm{Pt}(\mathrm{Me})_{3}$ is another example of a compound that has ligand based ionizations occurring before the metal based ionizations.

We have also started studying $\mathrm{Cp} * \mathrm{Rh}\left(\mathrm{PMe}_{3}\right)(\mathrm{Cl})(\mathrm{R})$ compounds, where $\mathrm{R}$ is chloride $(\mathrm{Cl})$, methyl $(\mathrm{Me})$ or phenyl $(\mathrm{Ph})$. These compounds do not show the unexpected electronic structure seen in $\mathrm{Cp} * \mathrm{Rh}\left(\mathrm{PMe}_{3}\right)(\mathrm{R})_{2}$. $\mathrm{The} \mathrm{Cl}$ ligand somehow effects the electronic structure so that it is analogous to other compounds. The first three ionizations are metal based, and the $\mathrm{Cp}$ and ligand based orbitals are at higher ionizations energies. The results thus far suggest that late transition metal species without $\mathrm{p}$ acceptor or electronegative ligands have frontier orbitals with a large amount of ligand character. In the absence of $\mathrm{p}$ acceptor ligands (such as $\mathrm{CO}$ ) or p donor ligands (such as $\mathrm{Cl}$ ), which could delocalize electron density from the metal center, the molecules must diffuse the charge. It apparently does so by mixing with $\mathrm{Cp}$ ring based orbitals, at least in the case of $\mathrm{Cp} * \mathrm{Rh}\left(\mathrm{PMe}_{3}\right)(\mathrm{R})_{2}$ compounds. The presence of a $\mathrm{Cp}$ ring appears to be an important prerequisite for this unusual electronic structure. This conjecture requires further investigation.

The PES of $\mathrm{Cp} * \mathrm{Rh}\left(\mathrm{PMe}_{3}\right) \mathrm{Me}_{2}$ strongly suggests a new type of electronic structure in rhodium compounds with $\mathrm{s}$ donor ligands only. We need to determine if this electronic structure exists in alkane $\mathrm{C}-\mathrm{H}$ activation products. Unfortunately, $\mathrm{Cp} * \mathrm{Rh}\left(\mathrm{PMe}_{3}\right)(\mathrm{H})\left(\mathrm{CH}_{3}\right)$ is not stable at room temperature and $\mathrm{Cp} * \mathrm{Rh}(\mathrm{PMe})(\mathrm{Ph})(\mathrm{H})$ decomposed in our instrument at $60 \mathrm{EC}$. These systems are good candidates for our new studies in the condensed phase. The photoelectron spectroscopy of the $\mathrm{Cp} * \operatorname{Ir}\left(\mathrm{PMe}_{3}\right)(\mathrm{R})(\mathrm{H})$ compounds (where $\mathrm{R}=\mathrm{H}, \mathrm{CH}_{3}$, $\mathrm{Ph}$, cyclohexyl) is an important extension of this work. The iridium compounds are significantly more stable than the rhodium analogs and are more likely to sublime before decomposition. This study will determine the electronic structure of alkyl hydride and aryl hydride compounds and show any differences in the bonding interactions of alkyl and aryl ligands. We observed differences in the bonding of $\mathrm{CH}_{3}$ and $\mathrm{Ph}$ in $\mathrm{Cp} * \mathrm{Rh}\left(\mathrm{PMe}_{3}\right)(\mathrm{Cl})(\mathrm{R})$ compounds; however, as happened above, the interactions may be different when the $\mathrm{Cl}$ is replaced by $\mathrm{H}$.
4. The Electronic Structure of $d^{4}$-Metal-Metal-? ${ }^{1}$-Alkynyls.
Lichtenberger, T. S. Wu, A. B. Uplinger. (DOE)
D. L.
Gas-phase ultraviolet photoelectron spectroscopy was used to investigate the electronic structure of $\mathrm{d}^{4}$ metal-metal-? ${ }^{1}$-alkynyls of the general formula $\mathrm{M}_{2}(\mathrm{P})_{4}(\mathrm{C} / \mathrm{C}-\mathrm{R})_{4}\left[\mathrm{M}=\mathrm{Mo} ; \mathrm{P}=\mathrm{PMe}_{3} ; \mathrm{R}=\mathrm{H}, \mathrm{Me}, \mathrm{SiMe}_{3}\right]$. The metal-metal $\mathrm{p}$ and $\mathrm{d}$ orbitals are able to have filled/filled interactions with the alkynyl p orbitals, but can also by symmetry donate electron density into the empty alkynyl p* orbital. All of the valence ionizations of the alkynyl complex are found to be substantially destabilized from those of the parent chloride complex. The energy difference

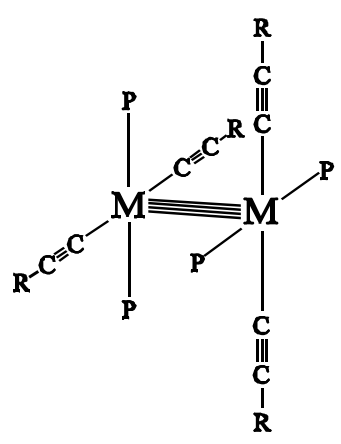


between the metal-metal $\mathrm{d}$ and metal-metal $\mathrm{p}$ ionizations was found to decrease in going from the parent chloride complex to the trimethylsilylalkynyl complex, which can be interpreted in terms of the influence of some backbonding into the alkynyl p* orbitals.

\section{Gas-Phase Photoelectron Spectroscopy of $\mathrm{CpNiNO}$ and $\mathrm{Cp}$ *NiNO: A "Resolution" to the Controversy. D. L. Lichtenberger and J. R. Pollard. (DOE)}

The utilization of different source energies in photoelectron spectroscopy is an effective method for determining the orbital character of transition metal complexes. Problems can arise when the resolution loss that accompanies higher energy ionization sources also effects the apparent relative intensities of overlapping ionization bands. Recent publications suggest different assignments for the gas-phase photoelectron spectrum of CpNiNO (Inorg. Chem. 35, 2504 and 2515). In order to eliminate resolution factors, we collected very high resolution $\mathrm{HeI}$ and $\mathrm{HeII}$ data $\left(13 \mathrm{meV} \mathrm{Ar}^{2} \mathrm{P}_{3 / 2}\right)$ on $\mathrm{CpNiNO}$. In addition, $\mathrm{Cp} * \mathrm{NiNO}$ was synthesized and $\mathrm{HeI}$ and HeII spectra were collected to observe how the more electron-donating $\mathrm{C}_{5}\left(\mathrm{CH}_{3}\right)_{5}$ ring would affect the ionization bands. These results show that experimental resolution plays an extremely important role in the assignment of the $\mathrm{CpNiNO}$ spectra.

6. Photoelectron Spectroscopy of Chiral Thiolate Complexes of the Type CpM(NO)(L)SMe (M= Re or $\mathbf{M n}, \mathbf{L}=\mathbf{P i P r}_{3}, \mathbf{P P h}_{3}$, or $\mathbf{P M e}_{3}$ ). N. Burzlaff, D. L. Lichtenberger, with W. A. Schenk (University of Würzberg) and K. R. Winfield. (DOE)

The valence electronic structures of $d^{6}$ chiral thiolate compounds of the general type CpM(NO)(L)SMe $\left(\mathrm{M}=\mathrm{Re}\right.$ or $\mathrm{Mn}, \mathrm{L}=\mathrm{P}^{\mathrm{i}} \mathrm{Pr}_{3}, \mathrm{PPh}_{3}$, or $\mathrm{PMe}_{3}$ ) and the isoelectronic complex $\mathrm{CpFe}(\mathrm{CO})_{2} \mathrm{SMe}$ are investigated via gas-phase photoelectron spectroscopy (PES). The assignments of the ionization bands are aided by analysis of $\mathrm{He}$ I and $\mathrm{He}$ II cross section trends and by modeling with Fenske-Hall molecular orbital calculations. A previous study of the isoelectronic complexes of the type $\mathrm{CpFe}(\mathrm{CO})_{2} \mathrm{SR}$ (Inorg. Chem. 1988, 27, 191), where $\mathrm{R}=\mathrm{C}_{6} \mathrm{H}_{4}-\mathrm{p}-\mathrm{Z} ; \mathrm{Z}=\mathrm{OMe}, \mathrm{H}, \mathrm{Cl}, \mathrm{CF}_{3}, \mathrm{NO}_{2}$, uses calculations and PES to show that the HOMO of these species is an antibonding $d p=p p$ interaction between the filled metal $d$ orbital and the sulfur $3 p$ lone pair.

7. Quantitative Evaluation of the Metal-Halide $p$ Interactions for Rhenium Pentacarbonyl Halides. N.E. Gruhn, D.L. Lichtenberger, and E.R. Russell. (DOE)

The electronic structures of $\operatorname{Re}(\mathrm{CO})_{5} \mathrm{X}$ have been studied by gas-phase photoelectron spectroscopy (PES). The atomic character of the valence orbitals has been determined by variable photon energy PES using Ne I, $\mathrm{He}$, and He II $(16.85,21.21$, and $40.8 \mathrm{eV}$, respectively) as ionization sources. A previous study of the He I PES of these complexes ( J. Am. Chem. Soc. 1975, 97, 2057-2065) used an analysis of the spin-orbit coupling from the rhenium and the halogens to conclude that the $\mathrm{HOMO}$ of $\mathrm{Re}(\mathrm{CO})_{5} \mathrm{Cl}$ is mainly rhenium in character, while the corresponding orbital of $\operatorname{Re}(\mathrm{CO})_{5} \mathrm{I}$ is mainly iodide in character. The spin-orbit coupling has been reevaluated with better resolution and signal-to-noise data than the previously reported spectra. Both the variable photon energy PES and spin-orbit analysis indicate that the HOMOs of $\operatorname{Re}(\mathrm{CO})_{5} \mathrm{X}$ complexes contain an even greater amount of halogen character than previously surmised.

8. Geometry and Substituent Effects on the Electronic Structure of Disilenes. D. L. Lichtenberger and N. E. Gruhn, (with R. West, N. Comerlato and H. Sohn, Department of Chemistry, University of Wisconsin). (PRF)

Photoelectron spectroscopy and molecular orbital calculations are used to examine the electronic structure of tetraaryl- and diaryldialkyl-substituted disilenes. Comparisons are also made to the analogous olefin compounds. The gas-phase HeI and HeII photoelectron spectra of tetramesityldisilene show the HOMO to be 
the Si-Si p-bond. This ionization is located at $7.52 \mathrm{eV}$. In comparison, the ionization from the olefin C-C pbond of tetraphenylethylene is located at $7.41 \mathrm{eV}$. The solid state structures of these compounds show the aromatic rings of tetraphenylethylene to be more nearly coplanar with the central double bond than the aromatic rings of tetramesityldisilene. The olefin C-C p-bond is destabilized compared to the disilene Si-Si p-bond due to a greater possibility for filled-filled interaction with the substituent aromatic rings.

9. Comparison of the Electronic Structure of Disilene, Silene, and Olefin Transition Metal Complexes. D. L. Lichtenberger and N. E. Gruhn, (with D. H. Berry, Department of Chemistry, University of Pennsylvania). (PRF)

Transition metal disilene, silene, and olefin complexes have been studied by gas-phase photoelectron spectroscopy and molecular orbital calculations. Specific complexes which have been studied by photoelectron spectroscopy include $\mathrm{Cp}_{2} \mathrm{~W}\left(\mathrm{Me}_{2} \mathrm{Si}=\mathrm{SiMe}{ }_{2}\right), \mathrm{Cp}_{2} \mathrm{~W}\left(\mathrm{Me}_{2} \mathrm{Si}=\mathrm{CH}_{2}\right)$, and $\mathrm{Cp}_{2} \mathrm{~W}\left(\mathrm{H}_{2} \mathrm{C}=\mathrm{CH}_{2}\right)$. The energy separation between the ligand p-to-metal $d p\left(1 a_{1}\right)$ orbital and metal dp-to-ligand $p^{*}\left(b_{2}\right)$ orbital of these complexes gets progressively smaller as the ligand is varied from olefin to silene to disilene. This is as would be expected from the $\mathrm{p}$ to $\mathrm{p}^{*}$ energy separations of unligated olefins, silenes, and disilenes. The first ionization of these compounds arises from the non-bonding $2 \mathrm{a}_{1}$ orbital of the formally $\mathrm{d}^{2}$ metal center. The trend in first ionization energies is olefin < silene < disilene. When the positions of the first ionizations are corrected for the inductive effect of the methyl substituents on the silene and disilene compounds, the ordering switches to disilene < silene < olefin. Overall, the bonding in these compounds appears to be quite similar.

10. Comparison of the Bonding in Chelated Triphos and Tris(tertiary amine) Rhodium Complexes. D. L. Lichtenberger and L. Subramanian, (with L. Wang and T. C. Flood, Department of Chemistry, University of Southern California). (DOE)

Various acidolysis reactions of $(\mathbf{A})(\mathrm{Cn}) \mathrm{RhMe}_{3}$ and $(\mathbf{B})$ (3P) $\mathrm{RhMe}_{3} \quad$ [where $\mathrm{Cn}=1,4,7$-trimethyl-1,4,7triazacyclononane, $\left.3 \mathrm{P}=\mathrm{CH}_{3} \mathrm{C}\left(\mathrm{CH}_{2} \mathrm{PMe}_{2}\right)_{3}\right]$ reveal large differences in their chemistries. Photoelectron spectroscopic studies on these systems provide insight into the nature of the HOMO and the differences in Rh-N and Rh-P bonding. The lowest ionization band in $(\mathrm{Cn}) \mathrm{RhMe}_{3}$ system is extremely narrow indicating the non-bonding nature of the metal $\mathrm{d}$ orbitals. In contrast, in (3P) $\mathrm{MeRh}_{3}$, it is considerably broad
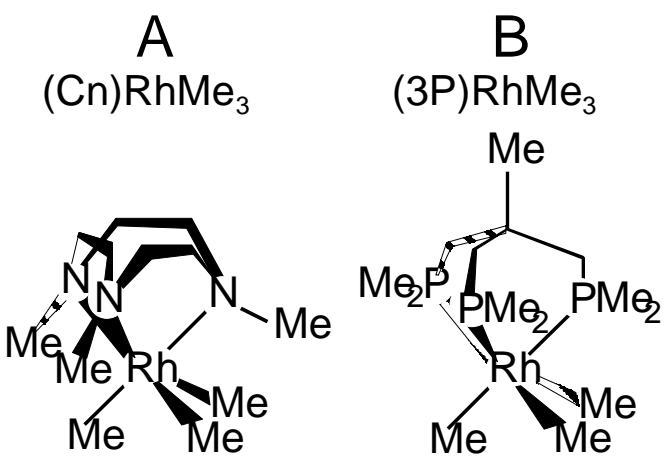
due to back-bonding interaction between the metal and phosphorus. Since the Rh-C s bond in $\mathbf{A}$ is at $8.0 \mathrm{eV}$ and that in $\mathbf{B}$ is at $10.0 \mathrm{eV}$ the former can be broken more easily than the latter.

11. Photoelectron Spectroscopy of Methyl-Substituted Ferrocenes. G. P. Darsey, D. L. Lichtenberger and J. K. Moberg (DOE).

The details of the electronic structure and bonding in substituted ferrocenes have been probed by photoelectron spectroscopy. The fundamental electronic interaction of the methyl group substituted for hydrogen on a metal-coordinated cyclopentadienyl ring is shown by a combined core and valence pe spectroscopic study of a series of methyl-substituted ferrocenes. High resolution gas-phase $\mathrm{He}(\mathrm{I})$ and $\mathrm{He}$ (II) photoelectron spectra for ferrocene, 1,1'-dimethylferrocene and decamethylferrocene have been collected. Detailed vibration progressions are evident. Previous low resolution studies of these complexes were unable to resolve significant vibrational structure in the lowest energy ionizations. Shifts of core and valence ionization energies upon methyl substitution are equivalent and additive for the iron atom. Knowledge of the 
core ionization energy shifts for both carbon and iron allow the relative changes in atomic charges upon methyl substitution to be found. In these molecules, the methyl group is found not to be an inductive electron donor compared to hydrogen as is commonly assumed. The primary electronic effect of the methyl substitution is on the valence orbitals of the cyclopentadienyl ring. Methylation of the cyclopentadienyl rings of the ferrocene causes a dramatic redistribution of valence electron density and greatly increases the covalent nature of metalring bonding.

\section{INSTRUMENTATION AND METHODS DEVELOPMENT}

As discussed in the proposals and previous progress reports, the continuing improvement in our experimental and computational capabilities for investigating these properties is an important aspect of this program. Several upgrades have been made on our existing gas-phase photoelectron spectrometer, and progress continues on the new second spectrometer. The prospects for experiments on the new spectrometer are particularly exciting. Our theoretical and modeling capabilities are also continuing to move forward. The acquisition of new programs and the modification and development of current software allows us to fully utilize the enhanced capabilities of our new computers and workstations in this department.

\section{Thin Film Surface Photoelectron Spectroscopy Development. UHV XPS/UPS/Auger Surface Spectroscopy.}

Our surface studies entering the present period were carried out on a VG ESCALAB MKII ultra-high vacuum surface analysis system. The analysis capabilities include dual-anode XPS, monochromatic XPS, 5micron Auger, HeI and He II UPS, and sputter ion sources. The main analysis chamber $\left(10-{ }^{11}\right.$ torr $)$ is attached to a special prep-entry chamber (10- ${ }^{9}$ torr) that is in turn attached to a specially designed gas-liquid-solid dosing cell that allows preparation of thin metal-complex films in ultra-high-vacuum. This instrumentation is maintained by Dr. Ken Nebesny, the staff scientist who directs our Laboratory for Electron Spectroscopy and Surface Analysis. We have developed techniques for precisely controlling the preparation of thin films of these metal complexes on any substrate in UHV, with coverages down to much less than a monolayer.

During the present period of this project we received major funding from NSF for purchase of a new surface analytical system with expanded capabilities. We have purchased and installed a Kratos 165 Ultra. This is a multi-technique UHV photoelectron spectrometer capable of recording real-time energy selected photoelectron images with a spatial resolution of 10 microns and below. Magnesium, zirconium and monochromatic aluminum excitation sources provide a range of sensitivites, energies, and resolutions for high sensitivity XPS analysis. High signal-to-noise ratios is provided via multi-channel detection. The spectrometer is also fitted with a Omicron high intensity ultra-violet discharge lamp for HeI and HeII photoelectron studies of the valence levels of solid surfaces. Heating, cooling and sample sputtering/automated depth profiling is likewise available. The system typically operates at a pressure of less than 1x10-9 torr to ensure sample cleanliness. Samples can be introduced via a fast entry lock; or the entire system can be coupled to custom laboratory built vacuums chambers for production and analysis of samples without exposure to atmospheric contamination. The entire system and subsequent data analysis is controlled by a Sun Sparc5 workstation which is fully networked to the departmental and university computer systems.

This system includes the following capabilities:

! Dual anode(Mg Ka and $\mathrm{Al} \mathrm{Ka}) \mathrm{X}$-ray photoelectron spectroscopy(XPS)

! Monochromatic Al Ka XPS

! High Intensity HeI/II/NeI lamp for Ultraviolet Photoelectron Spectroscopy

! Auger electron spectroscopy

! Argon ion sputtergun for sputter depth profiling and sample cleaning 
! Low energy electron flood gun for the analysis of insulators by both XPS and UPS

! Hemispherical Energy Analyzer/lens system with both small spot, imaging, and element mapping capabilities

! The capability to couple our current deposition chamber to do thin film analysis without leaving vacuum

! Resistively heated and LN2 cooled sample stages with XYZ and ? motion

We have also improved our capabilities for the surface electron spectroscopy of organometallic complexes with a UHV deposition system. A retractable Quartz Crystal Microbalance System was added to the system to measure deposition rates and coverages as close to the actual substrate position as possible. This was necessary to get accurate deposition rate information because of the narrow cross-section of the deposition source. To enhance our deposition capabilities to include air-sensitive compounds we have added a retractable Knudsen cell that is sealed with a gate valve. This allows the Knudsen cell to be loaded in a glove box or other controlled environment which can then be attached and evacuated in the pump down cycle of the chamber. This will aid in the study of air and water sensitive compounds in UHV.

A vapor/gas dosing source has also been added to the system which will allow the possibility of codeposition of highly volatile liquids or gases with compounds evaporated or sublimed from the Knudsen cell. This approach can be very useful for studying the effect of attachment of a coordinating ligand to a metal center of a compound and how it affects the valence and core-level energies in the thin film which can determined by XPS and UPS. The dosing source may also be used to look at the surface chemistry of compounds as they interact with low concentrations or coverages of a gas or highly volatile liquid. This reaction can also be followed by XPS and UPS.

\section{Gas-Phase Photoelectron Spectroscopy Development}

In 1995 the Department of Chemistry established a Departmental Facility in Gas-Phase Photoelectron Spectroscopy. Since this time, the photoelectron spectrometers used for this research have been part of a multiuser facility under the direction of Dr. Nadine E. Gruhn (state support), a staff scientist who received her Ph.D. training in my research group and who has an extensive background in photoelectron spectroscopy and its application to large molecules. We have also received funding from the National Science Foundation to build the next generation of gas-phase photoelectron spectrometer for large molecule investigations in the next period of research.

Some of the capabilities of our instrumentation have been described in our publications and in the renewal proposal. The heart of our instrument is a $36 \mathrm{~cm}$ hemispherical analyzer with a $8 \mathrm{~cm}$ gap around which we have developed improved excitation sources, sample handling, detection electronics, and computer control. All of these improvements have been necessary for the study of vibrational fine structure in the valence ionizations of metal complexes, and for the study of low volatility complexes. Several recent upgrades have been performed on the present photoelectron spectrometer. In particular, the detector signal-amplification electronics has been improved for an overall increase in instrument sensitivity by a factor of 10 . This increased sensitivity has opened the door to gas-phase investigations of chemical systems that were not possible previously.

Much of the information on electronic structure and bonding we are able to gain from gas-phase photoelectron spectroscopy comes from information we acquire by comparison of spectra of a molecule acquired with different ionization sources. Traditionally, He I and He II have been used as ionization sources, and we have designed and constructed sources with capabilities of creating a high flux of these photons. More recently we have gained experience with the use of Ne I photons as a third ionization source, and have found that evaluation of trends observed among spectra acquired with three sources can give additional information not available with two sources. 


\section{Theory and Molecular Modeling Developments}

Developments in computational chemistry and molecular modeling continue to have significant impact on this research program. At present we utilize Fenske-Hall, GAUSSIAN, and Amsterdam Density Functional (ADF) calculations. The ab initio calculations have yielded new insight into the limitations of Koopmans' Theorem. We have periodic trends in electron relaxation energies across the rows and down the columns of the transition metal series that assist in relating ionization energies to ground-state features of electronic structure. We are continuing to examine the ability of $a b$ initio and density functional methods to account for structures and ionization energies associated with metal-molecule interactions.

\section{LIST OF PUBLICATIONS AND PRESENTATIONS, September 1995-2000}

\section{A. Publications}

1. Lichtenberger, D. L.; Gruhn, N. E.; Rempe, M. E.; Geiger, W. E.; Chin, T. T. "Ligand-Mediated Metal-Metal Interactions in $\left(?^{5}: ?^{5}\right.$-fulvalene)bis(dicarbonylcobalt) and Rhodium Complexes." Inorg. Chim. Acta 1995, 240/1-2, 623-629.

2. Lichtenberger, D. L.; Gruhn, N. E.; Renshaw, S. K. "Relative Bonding Capabilities of Molecules to Metals as Measured by Gas-Phase Photoelectron Spectroscopy." J. Mol. Struct. 1997, 405, 79-86.

3. Lichtenberger, D. L.; Elkadi, Y.; Gruhn, N. E.; Hughes, R. P.; Curnow, O. J.; Zheng, X. "Electronic Structure Perturbations of Substituted Ruthenocenes: The First Photoelectron Spectra of Perchloro- and Perfluorocyclopentadienyl Complexes." Organometallics 1997, 16, 5209-5217.

4. Block, E.; Glass, R. S.; DeOrazio, R.; Lichtenberger, D. L.; Pollard, J. R.; Russell, E. E.; Schroeder, B.; Thiruvazhi, M.; Toscano, P. J. "Significant Intramolecular Sulfur-Sulfur Interactions in cis- and trans- 2,3-Dimethyl-5,6-dithiabicyclo[2.1.1] hexane." SYNLETT 1997, 5, 525-528.

5. Glass, R. S.; Pollard, J. R.; Schroed er, T. B.; Lichtenberger, D. L.; Block, E.; DeOrazio, R.; Guo, C.; Thiruvazhi, M. "Spectroscopic, Theoretical, and Electrochemical Studies of 1,2-Dithiins." Phosphorus, Sulfur, and Silicon 1997, 120 \& 121, 439-440.

6. Budzichowski, T. A.; Chisholm, M. H.; Tiedtke, D. B.; Gruhn, N. E.; Lichtenberger, D. L. "Preparation, Characterization and Electronic Structure of $\mathrm{W}_{2}\left(\mathrm{NMe}_{2}\right)_{2}\left(\mathrm{OR}_{\mathrm{f}}\right)_{4}$, Where $\mathrm{R}_{\mathrm{f}}=\mathrm{CMe}_{2} \mathrm{CF}_{3}, \mathrm{CMe}\left(\mathrm{CF}_{3}\right)_{2}$, and $\mathrm{C}\left(\mathrm{CF}_{3}\right)_{3}$ as Deduced by Photoelectron Spectroscopic Studies and the Single Crystal X-ray Structure for $\mathrm{R}_{\mathrm{f}}=\mathrm{OCMe}\left(\mathrm{CF}_{3}\right)_{2}$." Polyhedron 1998, 17(5-6), 705-711.

7. Gruhn, N. E.; Lichtenberger, D. L. "Characterization of the Electronic Structure of Transition Metal Carbonyls and Metallocenes." In Inorganic Electronic Structure and Spectroscopy; Vol. II: Applications and Case Studies; Lever, A. B. P.; Solomon, E. I., Eds.; John Wiley and Sons: New York, 1999, pp 533-574.

8. Cornil, J.; Vanderdonckt, S.; Lazzaroni, R.; dos Santos, D. A.; Thys, G.; Geise, H. J.; Yu, L.-M.; Szablewski, M.; Bloor, D.; Lögdlund, M.; Salaneck, W. R.; Gruhn, N. E.; Lichtenberger, D. L.; Lee, P. A.; Armstrong, N. R.; Brédas, J. L. "Valence Electronic Structure of p-Conjugated Materials: Simulation of the Ultraviolet Photoelectron Spectra with Semiempirical Hartree-Fock Approaches." Chem. Mater. 1999, 11, 2436-2443.

9. Gruhn, N. E.; Lichtenberger, D. L.; Ogura, H.; Walker, F. A. "Reevaluation of the Gas-Phase Valence Photoelectron Spectra of Octaethylporphyrin and Tetraphenylporphyrin." Inorg. Chem. 1999, 38, 4023-4027.

10. Fan, H.-J.; Carducci, M. D.; Grittini, C.; Mendoza, A.; Lichtenberger, D. L. "Crystal Structure of Phenylferrocene." Acta Cryst. 1999, C55, IUC9900154.

11. Lichtenberger, D. L.; Lynn, M. A.; Chisholm, M. H. "Quadruple Metal-Metal Bonds with Strong Donor Ligands. Ultraviolet Photoelectron Spectroscopy of $\mathrm{M}_{2}$ (form) $)_{4}(\mathrm{M}=\mathrm{Cr}$, Mo, W; form = N,N'-diphenylformamidinate)." J. Am. Chem. Soc. 1999, 121, 12167-12176. 
12. Lynn, M. A.; Lichtenberger, D. L. "Comparison of the Bonding of Benzene and $\mathrm{C}_{60}$ to a Metal Cluster: $\mathrm{Ru}_{3}(\mathrm{CO})_{9}\left(\mu^{3}-?^{2}, ?^{2}, ?^{2}-\mathrm{C}_{6} \mathrm{H}_{6}\right)$ and $\mathrm{Ru}_{3}(\mathrm{CO})_{9}\left(\mu^{3}-?^{2}, ?^{2}, ?^{2}-\mathrm{C}_{60}\right)$." J. Cluster Sci. 2000, 11 (1), 169-188.

13. Smith, K. J.; Ondracek, A. L.; Gruhn, N. E.; Lichtenberger, D. L.; Fanwick, P. E.; Walton, R. A. "A Comparative Study of the Isomers of $\mathrm{ReOCl}_{3}\left(\mathrm{PMe}_{3}\right)_{2}$ and $\mathrm{ReOCl}_{3}\left(\mathrm{PEt}_{3}\right)_{2}$. The Isolation and Characterization of $\mathrm{ReH}_{7}\left(\mathrm{PR}_{3}\right)_{2}$ and $\mathrm{ReO}(\mathrm{OEt}) \mathrm{Cl}_{2}\left(\mathrm{PR}_{3}\right)_{2}(\mathrm{R}=\mathrm{Me}$ or Et $)$ and the Photoelectron Spectrum of $\mathrm{ReH}_{7}\left(\mathrm{PMe}_{3}\right)_{2}$." Inorg. Chim. Acta 2000, 300-302, 23-31.

14. Lichtenberger, D. L.; Pollard, J. R.; Lynn, M. A.; Cotton, F. A.; Feng, X. "Metal-Metal Bonding in $\mathrm{Rh}_{2}\left(\mathrm{O}_{2} \mathrm{CCF}_{3}\right)_{4}$. Extensive Metal-Ligand Orbital Mixing Promoted by Filled Fluorine Orbitals." J. Am. Chem. Soc. 2000, 122 (13), 3182-3190.

15. Lichtenberger, D. L.; Fan, H.-J. G., N. E.; Bitterwolf, T. E.; Gallagher, S. "Electronic Structure of Early Transition-Metal Carbonyls: The Gas-Phase Photoelectron Spectroscopy of $\left(?^{5}-\mathrm{C}_{5} \mathrm{H}_{5}\right) \mathrm{M}(\mathrm{CO})_{4}(\mathrm{M}=$ V, Nb, Ta)." Organometallics 2000, 19, 2012-2021.

16. Glass, R. S.; Gruhn N. E.; Lichtenberger, D. L.; Lorance, E.; Pollard, J. R.; Birringer, M.; Block, E.; DeOrazio, R.; He C.; Shan, Z.; Zhang, X. "Gas-Phase Photoelectron Spectroscopic and Theoretical Studies of 1,2-Dichalcogenins: Ionization Energies, Orbital Assignments, and an Explanation of Their Color." J. Am. Chem. Soc. 2000, 122, 5065-5074.

17. Asirvatham, V. S.; Gruhn, N. E.; Lichtenberger, D. L.; Ashby, M. T. "Electronic Factors for Protonation of an Organometallic Molecule. A Photoelectron Spectroscopy and Electron Paramagnetic Resonance Study of $\left.\left(?^{6}-\mathrm{C}_{6} \mathrm{H}_{6}\right) \mathrm{Mo}(\mathrm{TRIPOD})\right]^{0 /+}$." Organometallics 2000, 19, 2215-2227.

18. Westcott, B. L.; Gruhn, N. E.; Michelsen, L. J.; Lichtenberger, D. L. "Experimental Observation of Non-Aufbau Behavior: The Photoelectron Spectrum of Vanadyloctaethylporphyrinate and Vanadylphthalocyanine." J. Am. Chem. Soc. 2000, 122, 8083-8084.

\section{B. Theses and Dissertations}

1. Pollard, J. R. "Ligand Effects and Periodic Trends in Metal-Metal Multiple Bonds: Theoretical and Experimental Studies of Electronic Structure by Gas-Phase Photoelectron Spectroscopy." Ph.D. Dissertation: The University of Arizona, 1996.

2. Winfield, K. R. "Photoelectron Spectroscopy of Transition Metal Thiolate Complexes: The Electronic Structures of $\left({ }^{5}-\mathrm{C}_{5} \mathrm{H}_{5}\right) \mathrm{Fe}(\mathrm{CO})_{2} \mathrm{SCH}_{3}$ and $\left(\eta^{5}-\mathrm{C}_{5} \mathrm{H}_{5}\right) \mathrm{Re}(\mathrm{NO})\left(\mathrm{PR}_{3}\right) \mathrm{SCH}_{3}(\mathrm{R}=$ isopropyl or phenyl)." M. S. Dissertation: The University of Arizona, 1997.

3. Uplinger, A. "The Electronic Structure and Bonding of Metal Acetylides." Ph.D. Dissertation: The University of Arizona, 1997.

4. Wu, T. S.-C. "Synthesis and Characterization of Metal-Acetylide Complexes"; Honors B. S. Thesis: The University of Arizona, 1998.

5. Fan, H.-J. "Photoelectron Spectroscopy and Computational Studies of Electron Delocalization in Organometallic Complexes"; Ph.D. Dissertation: The University of Arizona, 1999.

6. Lynn, M. A. "Metal, Ligand, and Symmetry Influences on Metal-Metal Bonds: Photoelectron Spectroscopy and Theory"; Ph. D. Dissertation: The University of Arizona, 2000. 


\section{Invited and Contributed Presentations}

1. "Silylenes and Disilenes: Equilibrium and Ionization." R. West, H. Spitzner, N.E. Gruhn and D.L. Lichtenberger, Organosilicon Symposium, Gainesville, FL, March 1995.

2. "Nature of Bonding in $\mathrm{RH}_{2}\left(\mathrm{O}_{2} \mathrm{CCF}_{3}\right)_{4}$." D.L. Lichtenberger and J.R.Pollard, 209 $9^{\text {th }}$ American Chemical Society National Meeting, Anaheim, CA, April 1995.

3. "Effects of Perhalogenation on $\left(?^{5}-\mathrm{C}_{5} \mathrm{X}_{5}\right)-\mathrm{Mn}(\mathrm{CO})_{3}(\mathrm{X}=\mathrm{Cl}, \mathrm{Br}, \mathrm{I})$." D.L. Lichtenberger, D. Crumpton, A. Kennedy and S. Gogosha, A. Uplinger, $209^{\text {th }}$ American Chemical Society National Meeting, Anaheim, CA, April 1995 (poster INOR 120).

4. "Extended Electronic Interactions in $\mathrm{CpRe}(\mathrm{NO})(\mathrm{CO}) \mathrm{R}$ Complexes: Vibrational Analysis of Re-H Bond Ionizations and Comparison with Re- $\mathrm{CH}_{3}$ Bond Ionizations." D.L. Lichtenberger, N.E. Gruhn, S.K. Renshaw, J.A. Gladysz, J. Seyler, and A. Igau, 210 ${ }^{\text {th }}$ ACS National Meeting, Chicago, IL, August 1995 (paper INOR 359).

5. "Relative Bonding Capabilities of Molecules to Metals by Gas Phase Photoelectron Spectroscopy." D.L. Lichtenberger and N.E. Gruhn, International Chemical Congress of Pacific Basin Societies, Honolulu, Hawaii, December 1995.

6. "Molecular and Electronic Structure Studies of 1,2-dithiine and Substituted Derivatives." D.L. Lichtenberger, R.S. Glass and J.R. Pollard, 211 ${ }^{\text {th }}$ National ACS meeting, 1996, New Orleans, Louisiana (poster INOR 199).

7. "Ligand Effects on Metal-Metal Interactions: The Relationship Between Rh-Rh Bonding and Catalytic Selectivity of $\mathrm{d}^{7}-\mathrm{d}^{7} \mathrm{Rh}_{2}$ Complexes." D.L. Lichtenberger and J.R. Pollard, $211^{\text {th }}$ National ACS meeting, 1996, New Orleans, Louisiana (paper INOR 354).

8. "The Electronic Characteristics of M-C Single-, Double-, and Triple-Bonds in Tetrahedral Complexes of Zr, Ta, and W, and the Effects of Silyl Substitution.” D.L. Lichtenber, J.M. Dunworth and N.E. Gruhn, $211^{\text {th }}$ National ACS meeting, 1996, New Orleans, Louisiana (poster INOR 143).

9. "Photoelectron Study of theFe-Fe Interaction in Bis(Fulvalene) Diiron; [Fulvalene $\left.=\left(?^{5}-\mathrm{C}_{5} \mathrm{H}_{4}: ?^{5}-\mathrm{C}_{5} \mathrm{H}_{4}\right)\right]$." D.L. Lichtenberger and $\underline{\text { H.Fan, }}$ 213 ${ }^{\text {th }}$ National ACS Meeting, San Francisco, CA, 1997 (poster INOR 132).

10. "The Binding of the $\mathrm{Ru}_{3}(\mathrm{CO})_{9}$ Fragment to Benzene, Fullerenes, and Graphite: the Interaction of a Metalcontaining Moiety with Aromatic $\mathrm{C}_{6}$-containing Surfaces." D.L. Lichtenberger and M.A. Lynn, $213^{\text {th }}$ National ACS Meeting, San Francisco, CA, 1997 (poster INOR 133).

11. "The Electronic Structure of d $\mathrm{d}^{4}$-Metal-Metal-? ${ }^{1}$-Acetylides." D.L. Lichtenberger, T.S. Wu, A.B. Uplinger, $213^{\text {th }}$ National ACS Meeting, San Francisco, CA, 1997 (poster INOR 134).

12. "Photoelectron Spectroscopy of Chiral Thiolate Complexes of the Type CpM(NO)(L)SMe (M= Re or Mn, $\mathrm{L}=\mathrm{P}^{\mathrm{i}} \mathrm{Pr}_{3}, \mathrm{PPh}_{3}$, or $\mathrm{PMe}_{3}$ )". N. Burzlaff, D.L. Lichtenberger, W.A. Schenk and K.R. Winfield, $213^{\text {th }}$ National ACS Meeting, San Francisco, CA, 1997 (poster INOR 135).

13. "Photoelectron Spectroscopy of Methyl-Substituted Ferrocenes." Gary P. Darsey, D.L. Lichtenberger and J.K. Moberg, 213 ${ }^{\text {th }}$ National ACS Meeting, San Francisco, CA, 1997 (poster INOR 136).

14. "Gas-Phase Photoelectron Spectroscopy of CpNiNO and Cp*NiNO: A "Resolution" to the Controversy." D.L. Lichtenberger and J.R. Pollard, 213 ${ }^{\text {th }}$ National ACS Meeting, San Francisco, CA, 1997.

15. "Photoelectron Spectroscopy of Dimetal Tetraformamidinates." D.L. Lichtenberger and M.A. Lynn, $213^{\text {th }}$ National ACS Meeting, San Francisco, CA, 1997.

16. "The Electronic Structure of $\mathrm{d}^{6}$ Metal-Acetylides." D.L. Lichtenberger, S.K. Renshaw, A.B. Uplinger, R.M. Bullock and M.G. Humphrey, 213 ${ }^{\text {th }}$ National ACS Meeting, San Francisco, CA, 1997.

17. Quantitative Evaluaton of the Metal-Halide $\mathrm{p}$ Interactions for Rhenium Pentacarbonyl Halides. N.E. Gruhn, D.L. Lichtenberger, and E.R. Russell, $214^{\text {th }}$ National ACS Meeting, Las Vegas, NV, September 1997 (poster INOR 35). 
18. "Experimental Measure of the Electron Distribution and Bonding in Transition Metal-Thiolate Complexes." N.E. Gruhn, D.L. Lichtenberger and K.R. Winfield, $214^{\text {th }}$ National ACS Meeting, Las Vegas, NV, September 1997.

19. "Electronic Structure Control of the Selectivity of Carbene Reactions Catalyzed by Rh-Rh Complexes." D.L. Lichtenberger and J.R. Pollard, 5th Chemical Congress of North America, Cancun, Mexico, 1997.

20. "New Aspects on Long-Range Metal-Metal Interactions in Bis(fulvalene)-diiron and Biferrocene." $\underline{H}-\mathrm{J}$. Fan and D.L. Lichtenberger, 215 ${ }^{\text {th }}$ National ACS Meeting, Dallas, TX; April 1998.

21. "The Rich Diversity of Metal-Metal Bonds. Factors that Influence Configurations from $\mathrm{s}^{2} \mathrm{p}^{4}$ to $\mathrm{s}^{2} \mathrm{p}^{4} \mathrm{~d}^{2} \mathrm{~d}^{* 2} \mathrm{p}^{* 4}$ as Determined by Photoelectron Spectroscopy," $215^{\text {th }}$ National ACS Meeting, Dallas, TX; March 1998.

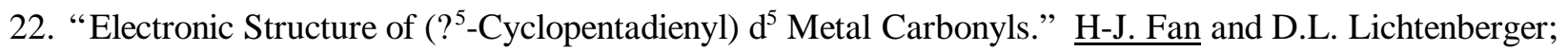
$216^{\text {th }}$ National ACS Meeting, Boston, Mass; August 1998.

23. "Ring-Tilt Effect on Electronic Structure of Bridging Ferrocene Compounds." $\quad$ H-J. Fan and D.L. Lichtenberger; $216^{\text {th }}$ National ACS Meeting, Boston, Mass; August 1998.

24. "UV Photoelectron Spectroscopy of Substituted $\mathrm{Mo}_{2}(\text { form })_{4}$ Systems: Correlation of Electronic and Overlap Effects in Solution and Gas Phases," M. A. Lynn, D. L. Lichtenberger and M. H. Chisholm; $217^{\text {th }}$ National ACS Meeting, Anaheim, California, March 1999. (Invited)

25. "Experimental Measure of Relative Photoionization Cross Sections of Molecular Functional Groups," J. Padden-Metzker, D. L. Lichtenberger and N. M. Gruhn; 217 ${ }^{\text {th }}$ National ACS Meeting, Anaheim, California, March 1999; poster 251.

26. "Valence and Core UHV Photoelectron Studies of Nonvolatile Organometallics," J. Padden-Metzker, D. L. Lichtenberger and P. Lee; 217 ${ }^{\text {th }}$ National ACS Meeting, Anaheim, California, March 1999; poster 252.

27. "Gas-Phase UV Photoelectron Spectroscopy of $\mathrm{M}_{2}$ (form $)_{4}(\mathrm{M}=\mathrm{Mo}, \mathrm{Ru}, \mathrm{Rh}, \mathrm{Pd}$; form $=N, N \mathrm{~N}$ diphenylformamidinate) Systems: Understanding the Metal-Metal Bonding Maniforld from ? to ?*," $\underline{\mathrm{M}}$. A. Lynn, D. L. Lichtenberger, and M. H. Chisholm; $217^{\text {th }}$ National ACS Meeting, Anaheim, California, March 1999; poster 253.

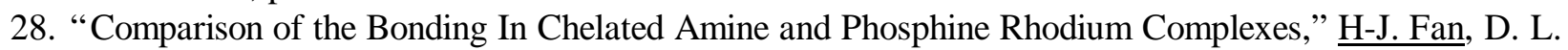
Lichtenberger, L. Want, T. C. Flood and L. Subramanian; 217 ${ }^{\text {th }}$ National ACS Meeting, Anaheim, California, March 1999; poster 254.

29. "Ne(I) Photoelectron Spectroscopy of Multiple Metal-Metal Bonds," J. B. English and D. L. Lichtenberger; $217^{\text {th }}$ National ACS Meeting, Anaheim, California, March 1999; poster 255.

30. "Photoelectron Spectroscopic Studies of Porphyrins and Metalloporphyrins," N. M. Gruhn, F. A. Walker and D. L. Lichtenberger; 217 ${ }^{\text {th }}$ National ACS Meeting, Anaheim, California, March 1999.

31. "Stereoelectronic Factors that Govern Kinetic and Thermodynamic Sites of Protonation of Some Organometallic Complexes," V. S. Asirvatham, N. E. Gruhn, D. L. Lichtenberger and M. T. Ashby; Royal Chemical Society: Fast Reactions in Solution, Lisbon, Portugal, September 1999. (Invited)

32. "Metal, Ligand, and Symmetry Influences on Metal-Metal Bonds: Photoelectron Spectroscopy and Theory," M. A. Lynn and D. L. Lichtenberger, 2000 Contemporary Inorganic Chemistry Symposium, Texas A\&M, College Station, March 2000.

33. "Metal-Metal Bonding in $\mathrm{Rh}_{2}\left(\mathrm{O}_{2} \mathrm{CCF}_{3}\right)_{4}$ : Extensive Metal-Ligand Orbital Mixing Promoted by Filled Fluorine Orbitals," D. L. Lichtenberger, J. R. Pollard, M. A. Lynn, F. W. Cotton and X. Feng, $219^{\text {th }}$ National ACS Meeting, San Francisco, California, March 2000, poster INOR 280.

34. "Metal-Metal Bonds with Strong Donor Ligands: An Ultraviolet Photoelectron Spectrscopic Study of $\mathrm{M}_{2}(\mathrm{mhp})_{4}(\mathrm{M}=\mathrm{Cr}, \mathrm{Mo}, \mathrm{W}, \mathrm{Ru}, \mathrm{Rh} ; \mathrm{mhp}=2$-methyl-6-oxopyridinate)," D. L. Lichtenberger, J. B. English, and M. A. Lynn, $219^{\text {th }}$ National ACS Meeting, San Francisco, California, March 2000, poster INOR 284. 
35. "Photoelectron Spectroscopy of First-Row Transition-Metal Complexes of Octaethylporphyrin,” R. E. Berry, N. E. Gruhn, D. L. Lichtenberger, and F. A. Walker, $219^{\text {th }}$ National ACS Meeting, San Francisco, California, March 2000, poster INOR 550.

36. "Evaluation of Metal-Pyridine $\mathrm{p}$ Interactions by Photoelectron Spectroscopy: Implications for Axial Bonding in Model Heme Compounds," N. E. Gruhn, F. A. Walker, and D. L. Lichtenberger, $219^{\text {th }}$ National ACS Meeting, San Francisco, California, March 2000, poster INOR 564.

37. "Photoelectron Spectroscopy of Tetrakis(2,6-dihalophenyl)porphyrins," S. R. Halper, N. E. Gruhn, D. L. Lichtenberger, and F. A. Walker; 219 ${ }^{\text {th }}$ National ACS Meeting, San Francisco, California, March 2000.

38. "Photoelectron Spectroscopic and Theoretical Studies of 1,2-Dichalcogenins Explaining their Color," $\underline{\mathrm{R}}$.

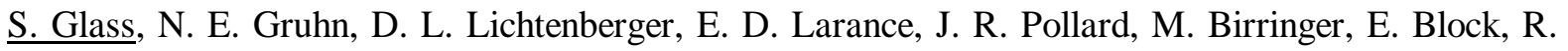
DeOrazio, C. He, Z. Shan and X. Zhang; $19^{\text {th }}$ International Symposium on the Organic Chemistry of Sulfur, University of Sheffield, UK, June 2000.

39. "Density Functional Theory Calculations on Molecules with Non-Aufbau Behavior: Vanadyl Octaethylporphyrinate and Vanadyl Phthalocyanine," D. L. Lichtenberger, N. E. Gruhn, L. J. Michelsen and B. L. Westcott; 220th ACS National Meeting, Washington, D.C. August 2000.

40. "Inverse Halogen Effect: Using Density Functional Theory and Photoelectron Spectroscopy to Explore Bonding in $\mathrm{M}_{2} \mathrm{X}_{4}\left(\mathrm{PMe}_{3}\right)_{4}(\mathrm{M}=\mathrm{Mo}, \mathrm{W}, \mathrm{Re} ; \mathrm{X}=$ Halogen $)$," J. B. English and D. L. Lichtenberger; 220th ACS National Meeting, Washington, D.C. August 2000.

41. "Application of Density Functional Theory to Photoelectron Spectroscopy: Using ADF to Understand Periodic Trends in Metal-Metal Bonded Systems," M. A. Lynn and D. L. Lichtenberger; 220th ACS National Meeting, Washington, D.C. August 2000.

\section{PERSONNEL}

\section{A. Postdoctoral Associates, Graduate Students, Undergraduates, and Staff, 1995-2000}

current associates in bold

1. Erin Russell, undergraduate assistant, 01/94-05/97, photoelectron spectroscopy of sulfur-sulfur lone pair interactions, applications of Ne I UPS to metal-halide interactions. B.S. degree with honors 05/97. She was recognized with the Nugent Award at commencement activities as one of the top six graduating seniors of the University.

2. Mirei Tanaka, undergraduate assistant, metal-nitrosyl complexes, 01/97-08/97.

3. John Pollard,; NSF postdoctoral research associate 07/96-07/97.

4. Kristie Winfield, DOE research associate, 01/96-08/97, metal-sulfur complexes; M.S. 08/97.

5. Rodney Ruddick, undergraduate assistant, 01/95-12/97, metal-acetylene complexes.

6. Olivia Oehrle-Steele, undergraduate assistant, 08/97-12/97, metal-sulfur complexes.

7. Teresa Wu, undergraduate assistant, 01/95-5/98, metal-acetylide complexes (Teresa has been nominated for the top senior awards at the University. She has been accepted to numerous medical schools and has accepted Johns Hopkins).

8. Andrew Uplinger, DOE research associate, 01/93-12/97, metal acetylides, C-H bond activation, and substituted cyclopentadienyls; Ph.D. 12/97; DOE postdoctoral research associate 01/98-07/98.

9. Jaret M. Sullivan, undergraduate assistant, 08/98-01/99.

10. Hua-Jun Fan, DOE research associate, 01/95-01/00, organic molecule-mediated metal-metal interactions, early metal carbonyls.

11. Julia Moberg, DOE research associate, 01/96-2000, correlation of core and valence ionizations of substituted ferrocenes, surface electron spectroscopy of adsorbed organometallic molecules.

12. Matthew Lynn, NSF Fellow, research associate, 08/96-05/00, Ph.D.; ligand effects on multiple metalmetal bonds. 
13. Jason English, NSF research associate, 01/97-present, multiple metal-metal bonds.

14. Laura Michelsen, graduate student supported by Department of Chemistry, 01/00-present, metalacetylene complexes (DOE project).

15. Laura Van Dorn, graduate student supported by Department of Chemistry, 01/00-present, catalysis of carbene reactions by rhodium dimers (NSF project).

16. Tonja Bill, graduate student supported by Department of Chemistry, 01/0-present, photoelectron spectroscopy of surface-anchored organometallics (DOE project).

17. Candice Fraser-Gaston, graduate student support by Department of Chemistry, 01/00-9/01, metal sulfur interactions (DOE project).

18. Aaron J. Riechers, undergraduate assistant, 05/99-9/01, metal-phosphine interactions.

19. Catherine E. Ott, undergraduate assistant, 02/99-12/99, preparation of surface-anchored organometallics.

20. Jaime Weisser, undergraduate assistant, 11/99-5/00, metal-pyridine interactions.

21. Sara R. Halper, undergraduate assistant, 08/99-5/00, metalloporphyrins.

22. Paul Lee, technical staff, 08/97-present, UHV developments.

23. Dona Myers, full time secretary serving this research group and the Enemark research group. Supported by the Department of Chemistry.

\section{B. Collaborators}

A major source of strength of this program is the cooperative efforts that have developed over the years. A number of research groups from across the country and around the world are interested in supplying samples for investigation by these techniques. Some groups assist in the theoretical aspects of these projects, while others contribute capabilities and expertise in the instrumentation aspects of the work. These cooperative efforts are not necessarily in the form of formal collaborative agreements. However, the progress in this research and the development of the present proposal owes much to the inspiration and contribution of these groups. A partial acknowledgment, in alphabetical order, would include:

N. R. Armstrong, University of Arizona; Michael T. Ashby, University of Oklahoma; V.S. Asirvatham, University of Oklahoma; Tom E. Bitterwolf, University of Idaho; Eric Block, SUNY, Albany; D. Bloor, University of Durham, U.K.; N. Burzlaff, Konstanz, Germary; Jean L. Brédas, University of Arizona; T.A. Budzichowski, University of Maryland, Baltimore County; R. Morris Bullock, Brookhaven National Laboratory; Michael D. Carducci, University of Arizona; Malcolm H. Chisholm, Indiana University; J. Cornil, Université de Mons-Hainaut, Belgium; F. A. Cotton, Texas A \& M; Owen J. Curnow, University of Canterbury, New Zealand; R. DeOrazio, SUNY, Albany; D. A. dos Santos, Université de Mons-Hainaut, Belgium; P. E. Fanwick, Purdue; Xuejun Feng, SUNY, Albany; Thomas C. Flood, University of Southern California; William Geiger, Jr., University of Vermont; H. J. Geise, University of Antwerpen, Belgium; John Gladysz, University of Utah; Richard S. Glass, University of Arizona; Nadine E. Gruhn, University of Arizona; C. Guo, SUNY, Albany; Russell Hughes, Dartmouth College; R. Lazzaroni, Université de Mons-Hainaut, Belgium; M. Lögdlund, Linköping University, Sweden; J.R. Lomprey, University of Kentucky; L. J. Michelsen, Central Connecticut University; A. L. Ondracek, Purdue; John R. Pollard, Coating Innovations, LLC, Tucson; Sharon K. Renshaw; W. R. Salaneck, Linköping University, Sweden; W. Schenk, Würzburg; T. B. Schroeder, University of Arizona; Ulrich Schubert, Würzburg; John P. Selegue, University of Kentucky; K. J. Smith, Purdue; M. Szablewski, University of Durham, U.K.; M. Thiruvazhi, SUNY, Albany; G. Thys, University of Antwerpen, Belgium; D.B. Tiedtke, Phillips Petroleum, Bartlesville, OK; Paul J. Toscano, SUNY, Albany; S. Vanderdonckt, Université de Mons-Hainaut, Belgium; F. Ann Walker, University of Arizona; R. A. Walton, Purdue; Robert West, University of Wisconsin, Madison; Barry Westcott, Central Connecticut State University, New Britain; L.-M. Yu, Facultés Univeritaires Notre-Dame de la Paix, 
Belgium; X. Zheng, SUNY, Albany; Andrew R. Barron (Rice University), Jack Beauchamp (Cal. Inst. Tech.), Tom Bitterwolf (University of Idaho), Malcolm H. Chisholm (Indiana University), Kim R. Dunbar (Michigan State University), Judith Eglin (Mississippi State University), John A. Gladysz (University of Utah), Harry B. Gray (Cal. Inst. Tech.), Roald Hoffman (Cornell University), Michael Hopkins (Pittsburgh), John L. Hubbard (Utah State University), Don Huffmann (University of Arizona), Russell P. Hughes (Dartmouth College), Mark Humphrey (Australian National University), Daniel L. Reger (University of South Carolina), David E. Richardson (University of Florida), Alfred F. Sattelberger (Los Alamos National Laboratory), Ulrich Schubert (Würzburg, West Germany), K. Peter C. Vollhardt (University of California, Berkeley), Richard A. Walton (Purdue University), Robert West (University of Wisconsin-Madison), Barry L. Westcott (Central Connecticut State University), Fred Wudl (UCLA). 